\title{
Postpartum family planning in Burkina Faso
}

Marina Daniele

Follow this and additional works at: https://knowledgecommons.popcouncil.org/departments_sbsr-rh

Part of the Demography, Population, and Ecology Commons, Family, Life Course, and Society Commons, International Public Health Commons, Maternal and Child Health Commons, Obstetrics and Gynecology Commons, and the Women's Health Commons How does access to this work benefit you? Let us know!

\section{Recommended Citation}

Daniele, Marina. 2014. "Postpartum family planning in Burkina Faso," STEP UP Research Report. London: London School of Hygiene and Tropical Medicine. 
STEP

STRENGTHENING EVIDENCE FOR PROGRAMMING ON UNINTENDED
PREGNANCY
BURKINA FASO

RESEARCH REPORT

FEBRUARY 2014

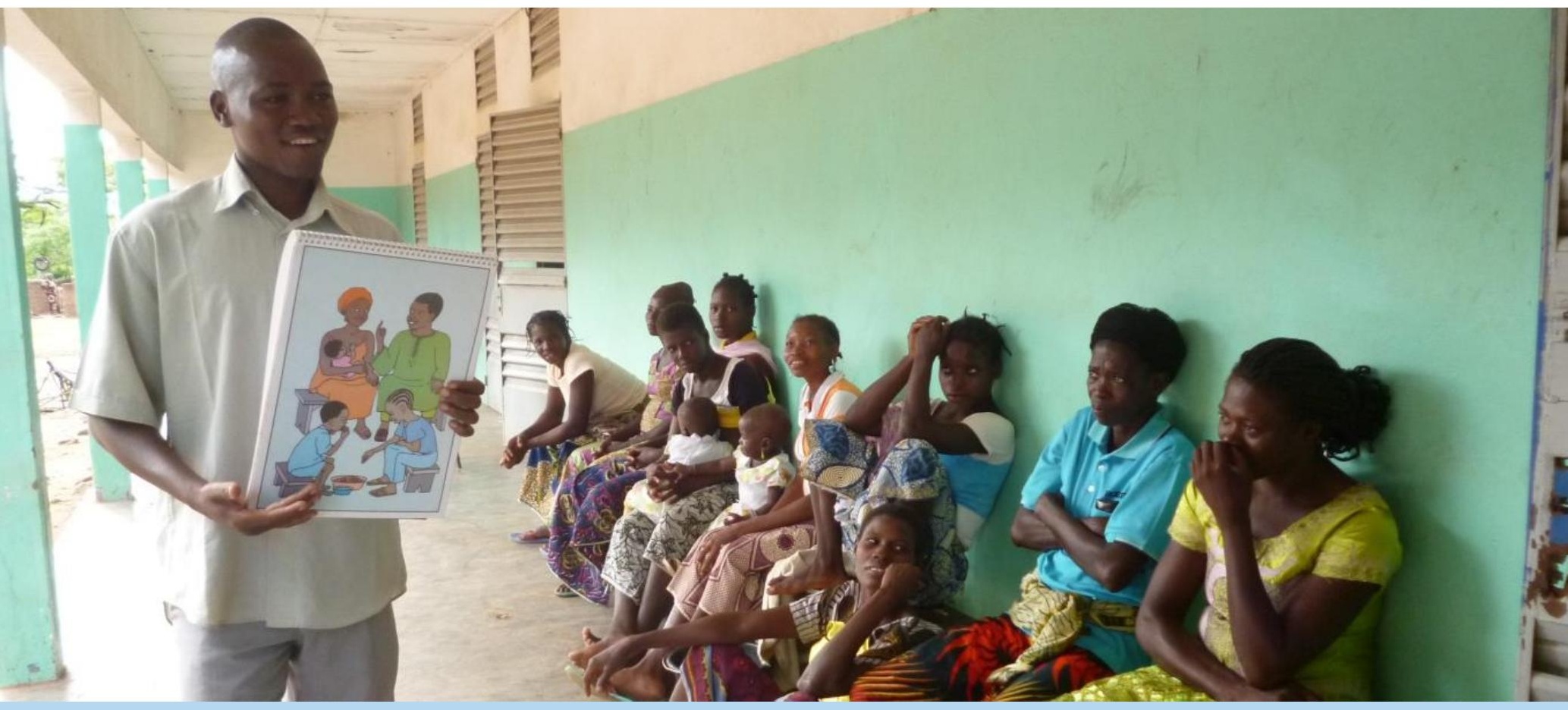

\section{Postpartum Family Planning in Burkina Faso}

MARINA DANIELE

\section{NT/4 \\ ThN UKaid}

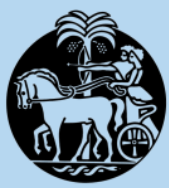




\title{
Postpartum Family Planning in Burkina Faso
}

\author{
MARINA DANIELE \\ London School of Hygiene and Tropical Medicine
}

February 2014 
The STEP UP (Strengthening Evidence for Programming on Unintended Pregnancy) Research Programme Consortium generates policy-relevant research to promote an evidence-based approach for improving access to family planning and safe abortion. STEP UP focuses its activities in five countries: Bangladesh, Ghana, India, Kenya and Senegal. STEP UP is coordinated by the Population Council in partnership with the African Population and Health Research Center; icddr, b; the London School of Hygiene and Tropical Medicine; Marie Stopes International and Partners in Population and Development. STEP UP is funded by UKaid from the UK Government. www.stepup.popcouncil.org

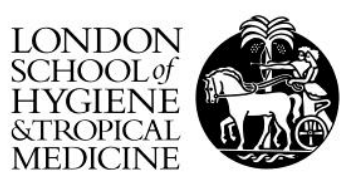

The London School of Hygiene \& Tropical Medicine is a world-leading centre for research and postgraduate education in public and global health. Our mission is to improve health and health equity in the UK and worldwide; working in partnership to achieve excellence in public and global health research, education and translation of knowledge into policy and practice. www.Ishtm.ac.uk

\section{(2) Population Council}

The Population Council confronts critical health and development issues-from stopping the spread of HIV to improving reproductive health and ensuring that young people lead full and productive lives. Through biomedical, social science and public health research in 50 countries, we work with our partners to deliver solutions that lead to more effective policies, programs and technologies that improve lives around the world. Established in 1952 and headquartered in New York, the Council is a nongovernmental, nonprofit organization governed by an international board of trustees. www.popcouncil.org

Suggested citation: Daniele, M. 2014. "Postpartum Family Planning in Burkina Faso," STEP UP Research Report. London: London School of Hygiene and Tropical Medicine.

\section{(c) 2014 LSHTM}

Please address any inquiries about STEP UP to the RPC co-directors:

Dr. Harriet Birungi, hbirungi@popcouncil.org

Dr. lan Askew, laskew@popcouncil.org

Funded by

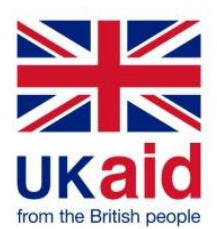




\section{Table of Contents}

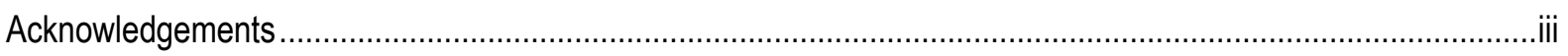

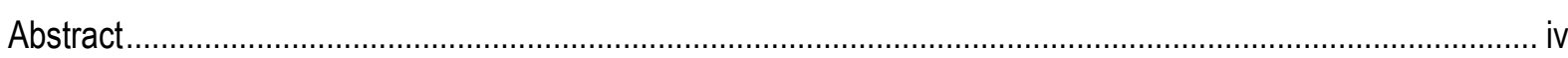

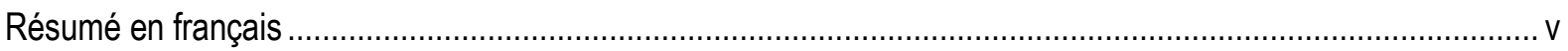

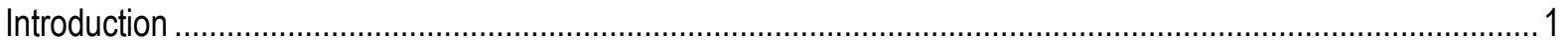

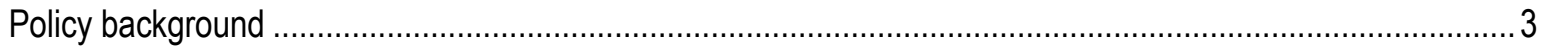

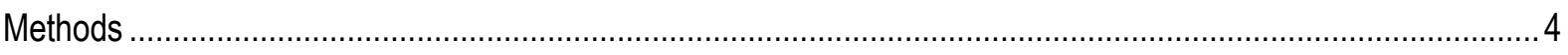

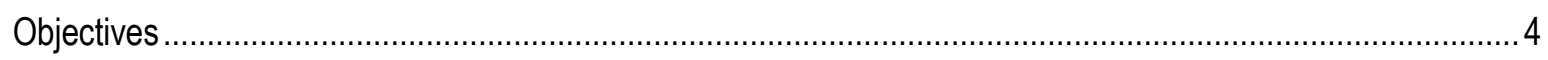

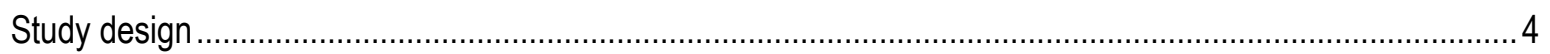

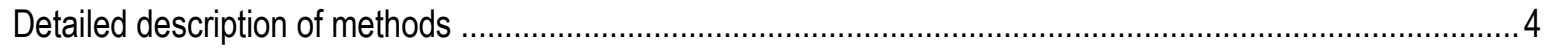

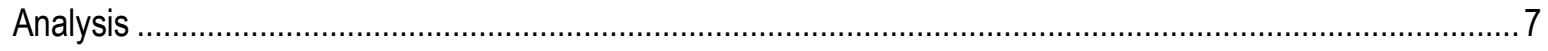

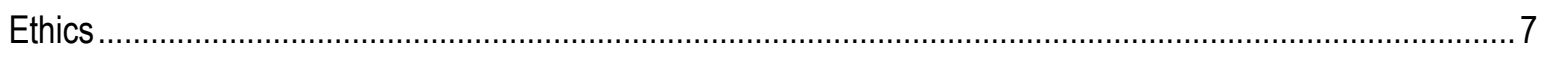

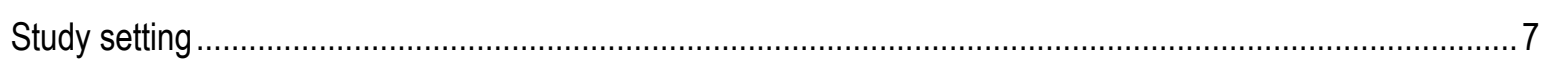

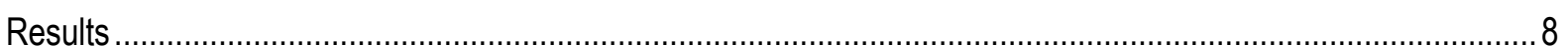

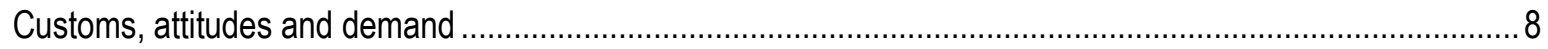

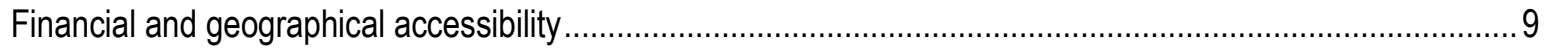

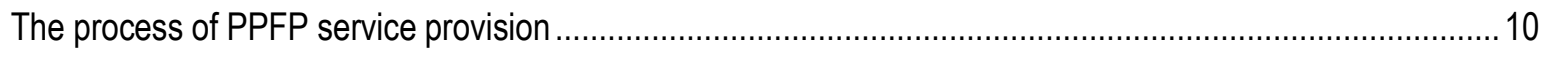

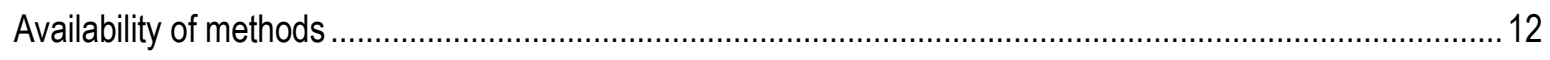

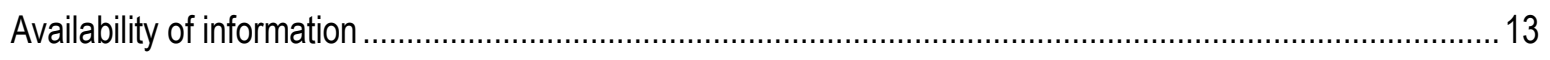

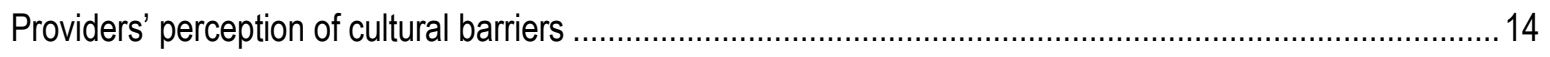

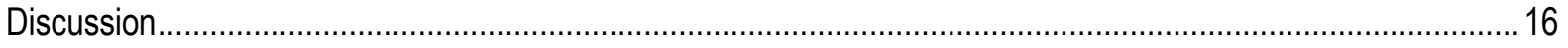

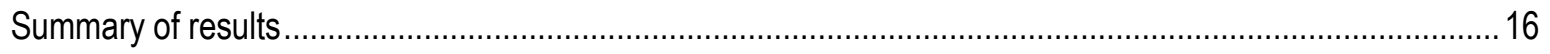

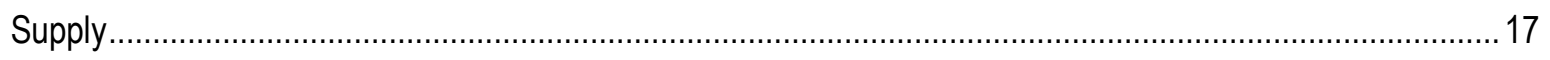

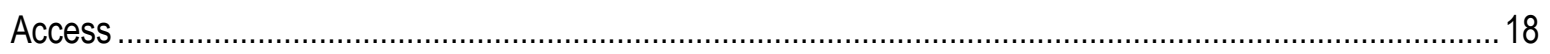

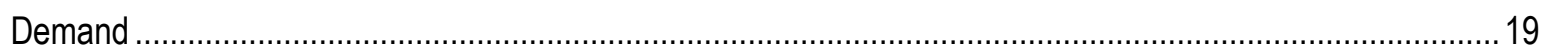

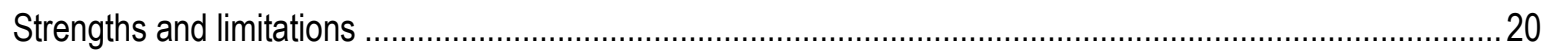

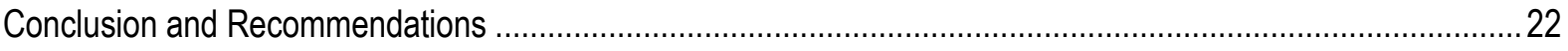

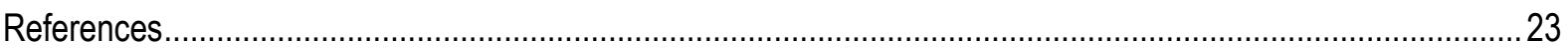




\section{Acknowledgements}

I would like to thank Dr. V. Filippi for all her support and encouragement. I am very grateful to the Population Council and the STEP-UP Consortium for financing this project and to the ESRC for funding my position at LSHTM. This project has been possible thanks to the affiliation with the study "Productivity, reproductive health and family planning: an inter-disciplinary study in Burkina Faso". This study is funded by the ESRC and paid for local senior staff time.

I am very grateful to Dr M. Yaogo and colleagues at AfricSante, in Bobo Dioulasso, for supporting me in my fieldwork. Many thanks also to Dr. Clementine Rossier (ISSP, Ouagadougou) and Dr. Fabienne Richard (ITG, Antwerp) for their help and advice. 


\section{Abstract}

Objective: This is a formative study aiming to identify the main barriers to the provision and uptake of quality postpartum family planning (PPFP) services at the supply, access, demand and policy levels in Burkina Faso.

Design \& Methods: A combination of three methods was used: a review of relevant literature, policy and clinical guidelines; observations of client-provider interactions in government-run primary health care centres in and around the city of Bobo-Dioulasso; and semi-structured interviews with stakeholders and key informants, including service providers and users.

Results: At the supply level, this study reveals that there are substantial shortfalls in the availability of quality postpartum family planning (PPFP). Individual counselling and the quality of information provided are often inadequate and occasions to advise women on family planning are wasted, resulting in low uptake of contraception during routine postnatal care. Providers appear to have an ambivalent and largely resigned attitude towards the possibility of enabling women to make informed choices, and towards the potential involvement of men. Services offer a limited range of methods due to a variety of factors including the lack of competent staff, stock issues, and provider biases. Furthermore, legal barriers are in place which prevent the majority of maternity staff from providing long-acting reversible contraception (LARC). The accessibility of services is limited by geographical and cost barriers. Cultural traditions and practices and high desired family size place limits on the demand for modern contraception, which is not well understood or acceptable to many people. Notable policy gaps exist in relation to user fees and to authorising maternity staff to provide LARC, and some national clinical guidelines are in need of improvement. However, most of the difficulties observed in the provision of PPFP services are in fact due to the failure to translate largely sound policies and guidelines into practice.

Conclusions: This study contributes to identifying priority areas and makes recommendations for improvement in order to respond to unmet need for family planning in the postpartum. Furthermore, it suggests that there may be a margin for the expansion of demand, and that improving quality of care could play a role in this. 


\section{Résumé en français}

\section{LA PLANIFICATION FAMILIALE POSTPARTUM AU BURKINA FASO}

\section{Objectifs de l'étude}

1 - Donner un aperçu de la disponibilité et la qualité des services prénatals, du post-partum (PP) et de planification familiale (PF) au niveau des soins primaires, et évaluer la mesure dans laquelle ils fournissent des services efficaces de planification familiale postpartum (PFPP)

2 - Evaluer l'accessibilité des services PFPP

3 - Explorer l'effet de facteurs sociaux , économiques et culturels sur la demande et l'adoption de la PFPP 4 - Estimer l'impact, la pertinence et la mise en œuvre de la politique nationale et des protocoles cliniques par rapport à la PFPP

5 - Identifier les principaux obstacles qui empêchent une réponse efficace aux besoins non satisfaits en matière de PPFP aux niveaux de l'offre, de l'accès et de la demande, et proposer des domaines d'amélioration potentiels.

\section{Méthodologie :}

Un ensemble de trois méthodes qualitatives a été utilisée: une revue de la littérature et des politiques et documents clés, 20 entretiens semi -structurés avec usagers et d'autres parties prenantes, y compris les prestataires de soins, et 12 jours d'observation des interactions client - prestataire dans 4 CSPS ( 2 en milieu urbain, 2 en milieu rural). Le travail de terrain a été réalisée lors d'une visite de 5 semaines au Burkina en été 2013. Les observations dans les CSPS ont été réalisées dans le District de Dafra (Bobo-Dioulasso).

\section{Sommaire des résultats :}

Du point de vue de l'offre (Objectif 1), cette étude révèle d'importantes lacunes dans la disponibilité des services de PFPP de qualité dans les centres de soins primaires. Aucune discussion sur la préparation au postpartum, l'allaitement ou la PF a lieu lors des consultations prénatales individuelles. Dans les consultations postpartum, la qualité du counseling en PF n'est pas fiable et semble dépendre en grande partie du prestataire individuel. La PF n'est pas toujours mentionné lors des consultations de la sixième heure et du sixième jour. Ainsi, même si la contraception est offerte à la sixième semaine, nombreuses femmes ne sont pas prêtes à adopter une méthode: elles sont soit pas au courant qu'elles auraient dû faire un choix, soit elles n'ont pas été correctement conseillées lors tout contact précédent, ou bien elles n'ont pas apporté assez d'argent. Quel que soit le moment dans lequel les consultations ont lieu, les prestataires ne prennent généralement pas en compte I'histoire contraceptive de la femme ou les circonstances de sa vie, afin d'encourager le choix de la méthode la plus approprié et d'identifier le moment optimal pour son adoption. Les femmes ne sont pas toujours informées de l'ensemble des méthodes disponibles ou des effets secondaires, en partie en raison des préjugés des prestataires contre certaines méthodes, et aucun effort n'est fait pour encourager les hommes à participer aux consultations. L'attitude des prestataires en ce qui concerne la possibilité d'informer adéquatement les femmes et la participation des hommes est ambivalente et largement découragé. L'éventail des méthodes actuellement disponibles est limité, en raison des facteurs suivants: ruptures de stock, réticence des prestataires à faire connaître et fournir certaines méthodes, et manque de compétences. II faut ajouter aussi le fait que la politique actuelle en matière de santé de la reproduction empêche aux accoucheuses de fournir les méthodes contraceptives réversibles à longue durée d'action comme l'implant et le DIU.

En ce qui concerne l'accès ( $\underline{\text { Objectif } 2}$ ), les femmes font face à des obstacles géographiques et ainsi les rendezvous de routine à 6 jours et 6 semaines après l'accouchement sont peu fréquentés. Les transferts pour obtenir une méthode qui n'est pas disponible localement sont très difficiles. Le coût des produits contraceptifs reste aussi une barrière significative (par exemple, le DIU coûte 800 CFA et l'implant 1000 CFA). La politique d'exemption pour d'autres consommables (pour l'insertion et le retrait de l'implant et du DIU) n'est pas pleinement appliquée. Malgré tout, d'autres occasions dans le continuum des soins sont gaspillées au cours 
lesquelles on pourrait fournir des conseils sur la PF, y compris la consultation prénatale (CPN). Les femmes aménorrhéiques qui exigent une méthode contraceptive plus de six semaines après l'accouchement rencontrent des obstacles spécifiques, tels que le prix du test de grossesse (entre 650 et 1500 CFA), ou l'exigence de stimuler une hémorragie de privation.

La demande et l'adoption de la PF (Objectif 3 ) sont généralement faibles pendant le postpartum. Bien que l'espacement des naissances soit estimé, il est possible que le désir d'une famille nombreuse joue un rôle dans la détermination de la faible demande. En outre, la persistance de coutumes spécifiques et les normes sociales telles que la séparation des époux et l'abstinence pendant le post-partum ont encore un impact sur l'adoption de la contraception, en particulier dans les zones rurales. L'opposition des hommes à la PF apparaît comme un thème fort. Le manque d'informations et les rumeurs contribuent également à donner à la contraception moderne une mauvaise réputation.

Des obstacles importants existent au niveau des politiques sur la PFPP (Objectif 4 ), surtout en ce qui concerne les coûts d'utilisation et le manque d'autorisation aux accoucheuses de fournir les méthodes contraceptives à longue durée. Bien qu'au niveau national le protocole clinique général sur la PF et les outils de supervision existants soient suffisants, le protocole spécifique sur les soins postnatals ne donne pas beaucoup d'espace à la contraception. En tout cas, les résultats de cette étude montrent qu'il y a souvent un écart important entre les politiques et les protocoles, et leur application pratique dans l'offre de soins quotidien.

\section{Recommandations (Objectif 5):}

Premièrement, des mesures doivent être prises pour améliorer la qualité de l'offre de services de PFPP. La présence d'agents de santé compétents et motivés qui sont autorisés et soutenus pour fournir des bons soins doit être garantie. À cet égard, les domaines d'action sont au niveau de formation pré-emploi et en cours d'emploi, ainsi que la supervision et soutien au personnel. Afin de pallier le manque de sages-femmes dans les zones rurales, il faudrait envisager de permettre aux accoucheuses d'être formés pour fournir les méthodes à longue durée, au moins comme stratégie de court terme. Le respect des protocoles cliniques devrait être amélioré, notamment en ce qui concerne le counseling et la fourniture d'informations. Dans des protocoles cliniques largement suffisants, des améliorations pourraient cependant être apportées. L'amélioration des compétences du personnel contribuera à rendre disponible une plus large gamme de méthodes contraceptives dans tout le pays. D'autres mesures sont aussi nécessaires pour éviter la récurrence des ruptures.

Deuxièmement, afin de faciliter l'accès et d'améliorer l'utilisation, il est nécessaire de faire un meilleur usage des possibilités existantes pour promouvoir la FP dans le continuum de soins. La mise en œuvre et l'amélioration du protocole sur les consultations prénatales (CPN) permettrait que la PF soit abordée déjà lors des soins prénatals, et d'autres mesures pourraient être prises pour promouvoir la préparation au postpartum et à la PFPP, à côté de la préparation à l'accouchement. L'élimination complète des paiements des utilisateurs en matière de contraception est nécessaire afin de faciliter l'accès, notamment pour les femmes les plus défavorisées.

Enfin, il est nécessaire de commencer à remettre en question la croyance répandue selon laquelle la culture traditionnelle est irrémédiablement hostile à la $\mathrm{PF}$, et de réaliser que les services de haute qualité ont le potentiel de stimuler la demande. À cet égard, fournir des conseils personnalisés et permettre un choix éclairé doivent devenir partie de la pratique courante. A cet effet, le développement d'une relation de confiance mutuelle entre prestataire et client est crucial. Promouvoir la participation des hommes a également le potentiel d'accroître la légitimité et promouvoir l'adoption de la PFPP. 


\section{Introduction}

High fertility is a major problem in Burkina Faso and the country's contraceptive prevalence rate (CPR) remains one of the lowest in the world. Despite the CPR having improved from $9 \%$ of women in union in 2003 to $15 \%$ in 2010, the total fertility rate (TFR) remains high at 6.0 births per woman, and has hardly changed since $2003(6.2)$ (INSD 2012). So far, progress on the CPR has been insufficient to have a noticeable impact on fertility: a $15 \%$ increase in CPR is normally needed to reduce the TFR by one birth per woman (Cleland et al, 2011). Thus, further increasing contraceptive prevalence among the reproductive age population is imperative in order to reduce total fertility.

There are many good reasons why programmes aiming to increase contraceptive prevalence should focus on the postpartum. Antenatal, childbirth and postnatal care have the potential to make contact with a large proportion of the population, and to promote a culture of careseeking for broader preventative and curative services, including family planning (FP). The WHO considers maternity services to be a point of entry for interventions in reproductive and sexual health (WHO, 2004 b) and an international consensus now exists on the fact that linking FP to the MCH continuity of care pathway provides an "array of opportunities" and "more acceptable, timely and effective ways of reaching postpartum women and addressing their FP needs" (WHO et al. 2012). Research by the Population Council has shown that the integration of spacing messages into prenatal and postnatal consultations can increase contraceptive use in the postpartum (Abdel-Tawab et al, 2008). It may also be cost-effective for FP programmes to make use of existing resources for $\mathrm{MCH}$ (Singh et al., 2009). Furthermore, making good use of every opportunity to build on and develop women's sense of entitlement to control over their reproduction can have far broader societal and economic repercussions (Bongaarts, 1994).

Although the postpartum has been hailed as a period when unmet need for contraception is particularly high in developing countries (Ross and Winfrey, 2001), it has since been recognized that, in West Africa, the notion of "postpartum unsusceptibility" to pregnancy (Bongaarts and Potters, 1983) still applies to a particularly large proportion of postpartum women (Brown, 2006). This is due to long periods of amenorrhea related to breastfeeding, and to the existence of a strong tradition of postpartum abstinence (Page and Lesthaeghe, 1981). In Burkina Faso, DHS data show that 59\% of women are still unsusceptible at 1 year postpartum (INSD, 2012). Thus, the proportion with unmet need does not take into account this majority of women, who are not in fact at risk of pregnancy and thus do not have a need for contraception. For the women who are susceptible, DHS data show that the level of unmet need in the first year after birth is high, although hardly higher than for all reproductive age women in a union (25\%, compared to $24 \%)^{1}($ INSD, 2012).

However, focusing on postpartum family planning (PPFP) is essential even in West Africa, or perhaps particularly so. The length of postpartum unsusceptibility is declining as a result of urbanisation, economic development, and social and cultural changes. In the future, this could lead to an increasing proportion of women being at risk of unwanted pregnancy if quality PPFP services do not step in to fill the gap. In Burkina Faso, the median length of unsusceptibility was 19.9 months in 2003 and has now reduced to 15.0 (INSD, 2004 and 2012). The median duration of breastfeeding, key to amenorrhea, has already begun to decline between 2003 and 2010 and is less among urban and wealthier women (INSD, 2012). This may well decline further as more women enter the workforce and are unable to feed their babies as frequently. In the same period, the median duration of postpartum abstinence has also fallen from 12.5 months to 7.7 between 2003 and 2010 . These changes are likely to undermine the current fertility-containing effect of postpartum unsusceptibility.

\footnotetext{
1 Own calculation, given that $42.4 \%$ of women are susceptible to pregnancy at 1 year postpartum, assuming that levels of met need are the same as for all women (41\%) (INSD, 2012)
} 
Furthermore, although in the last 10 years the median birth interval has remained stable at 3 years (INSD, 2012), the shortening of postpartum unsusceptibility may cause this to reduce in the future. Thus, promoting PPFP will become an even stronger imperative, if the current healthy birth intervals are to be maintained, or improved. Using data from different countries, a correlation has already been demonstrated between the use of contraceptives and longer birth intervals (Cleland et al, 2006).

In Burkina Faso, the link between rapid population growth and development has been recognized for some time (Ministry of the Economy and Finances, 2000 and 2011), and the importance of FP for the achievement of MDGs 4 and 5 has been acknowledged (Ministry of Health, 2006). FP plays a prominent role within reproductive health policy and MCH protocols (Ministry of health, 2010 a and $2010 \mathrm{c}$ ). The government has committed to increase the proportion it contributes relative to donors to the purchase of contraceptives to $70 \%$ by 2015 (Ministry of Health, 2005). In 2013, a plan was issued setting targets for the increase in CPR by Region (Ministry of Health, 2013). However, despite an annual population growth of $3.1 \%$ (INSD, 2006), no population targets have been set, nor has the CPR been included among progress indicators for the current 10-year National Health Development Plan (Ministry of Health, 2011). Thus, the slow progress made so far in increasing the CPR calls for investigations into potential shortfalls on the supply side, whether due to policy gaps or to lack of implementation.

On the other hand, despite being one of the countries with the highest levels of unmet need, the extent to which the demand for family planning really exists among the population must also be questioned. Desired family size has not changed since 2003 and remains high, at 5.5 children per woman. The unmet need for limiting births is nearly 3 times lower than that for spacing (INSD, 2012). An ambivalent attitude towards the continuation of childbearing within a pronatalist culture and the unwillingness to commit to cessation (Page and Lesthaeghe, 1981) may play some role in explaining high reported desired fertility. Furthermore, FP has not yet gained complete acceptance: over a third of women say they do not intend to use contraception in the future, and the reasons for this need to be explored (INSD, 2012).

This study aims to assess the extent to which quality FP services are available to postpartum women in Burkina Faso, and reflect on the relative importance of potential barriers to the uptake of contraception at the supply, access, demand and policy levels. The ultimate goal of the study is to identify priority areas for improvement in the integration of FP with $\mathrm{MCH}$ services, which can then be the object of further research.

This is a formative study carried out in the context of a larger research project by the title "Productivity, reproductive health and family planning: an inter-disciplinary study in Burkina Faso", which aims to assess the relationship between women's work and reproductive health outcomes. This study runs from December 2012 to November 2014 and includes a secondary analysis of existing data, a cohort study, and an anthropological study in Bobo-Dioulasso and surrounding villages. It is a collaboration between LSHTM, AfricSante, University of Oslo and Lariss and is embedded within the STEP-UP consortium. The results of the formative study will provide background information which will be useful to the conduct of the parent study. AfricSante provided assistance and logistical support for fieldwork in Burkina Faso, however, the identification of key informants and fieldwork sites took place independently of the parent study. 


\section{Policy background}

The national health system in Burkina Faso is composed of three tiers. At the first or national level there are 4 university teaching hospitals (Centre Hospitalier Universitaire or $\mathrm{CHU}$ ). At the second or regional level are 9 regional hospitals (Centre Hospitalier Regional or CHR). At the third or district level there are 44 District hospitals (Centre medical avec antenne chirurgicale or CMA) and 51 District hospitals not providing surgical care (Centre Medical or CM). Within districts, there are also 1495 primary care centres known as Centres de Sante' et de Promotion Sociale or CSPS (Ministry of Health 2012 b).

The health system is characterised by a scarcity of skilled providers in the field of maternal and reproductive health. In the last decade, the increase in the number of CSPS has not been matched by a corresponding increase in the number of midwives. The number of midwives pro capita is still considerably lower (at 1/12702) than the WHO standard of 1/3000 (Ministry of Health 2012 b). The government's response has been the recruitment of accoucheuses auxiliaires and their deployment to the rural areas, whilst midwives have been concentrated in referral hospitals. Between 200 and 300 midwives are qualifying every year in $\mathrm{BF}$, and the total number of midwives in the country has almost doubled since 2008. However, accoucheuses still outnumber midwives by more than 2 per 1, and virtually all midwives work in the cities (Ministry of Health, 2011 a). In urban CSPSs, midwives and accoucheuses work side by side, whereas in rural areas the accoucheuse is the sole provider of maternity and FP services. The accoucheuse is the professional who attends by far the largest number of births and provides the highest number of ANC and PNC consultations (INSD, 2012). These professionals have a basic level of primary education (Certificat d'edudes primaries elementaires) and have completed a two-year training programme (Ecole de santé publique, 1999). Since 2013, the government has abandoned the accoucheuse programme and will be training only midwives in the future.

All professionals involved in maternity care are authorised to administer natural FP methods, barrier methods and combined oral contraceptives (COC). This includes accoucheuses and community health workers (agents itinerants de santé or AIS), although the latter can administer but not prescribe. However, injectables, implants and IDUs can only be given by a category of highly qualified nurses (Infermier d'Etat or IDE), female and male midwives (Sage Femme d'Etat or SFE and Maieuticien d'Etat or ME), mid-level providers (Attaches de Sante') and doctors (Ministry of Health, 2010 a). In practice, accoucheuses also provide injectables.

Reproductive health policy provides for women to attend at least one antenatal visit per trimester, plus another before birth. In the postpartum, women and newborns are expected to return at 6 days and 6 weeks after birth. There is an established vaccination calendar for infants aged up to 16-18 months, plus monthly contacts for child growth check-ups in the first year. Information, education and communication (IEC) on a variety of topics, including family planning, is supposed to be provided to women and families by maternity services during the antenatal and postnatal periods, and during child care visits (Ministry of Health, $2010 \mathrm{a}$ ).

Antenatal, postnatal, child growth consultations and vaccinations are free for all (Ministry of Health, 2002). The cost of normal birth, caesarean section and emergency obstetric care are subsidised by $60-80 \%$ since 2006 . The cost is waived for the poorest $20 \%$ of the population and transport in the case of complications is also free (Ministry of Health, 2006 a). Contraceptives are subsidised, but 25\% of the price is still paid by users. The prices of contraceptives are supposed to be revised every year at the national level and are currently as follows: male condom 10 CFA, female condom 100, pill 100 per pack, injectable 500, implant 1000, IUD 800 (Ministry of Health, 2005). Accessory products needed for insertion, check-ups and reversal of methods are supposed to be free (Ministry of Health, $2011 \mathrm{~b}$ ). Antenatal care booklets and family planning cards are also free. The consent of the husband is not required to access any reversible contraceptive method, but the policy stresses the importance of dialogue within the couple (Ministry of Health, 2010 a). 


\section{Methods}

\section{Objectives}

1 To provide an overview of the availability and quality of antenatal, postpartum and FP services at the primary care level, and to assess the extent to which they effectively supply PPFP services

2 To assess the accessibility of PPFP services

3 To explore the effect of social, economic and cultural factors on the demand for and uptake of PPFP

4 To reflect on the appropriateness of national policy and clinical guidance relative to PPFP and on the degree to which this is implemented

5 To identify the most significant barriers to meeting unmet need for PPFP at the supply, access and demand levels and suggest potential areas for improvement.

\section{Study design}

A combination of three methods was used: a literature and policy review, semi-structured interviews with service users and other stakeholders, including providers, and the observation of client-provider interactions in 4 CSPS. Fieldwork was carried out in the Bobo-Dioulasso area during a 5-week visit in the summer of 2013. This combination of methods was deemed appropriate to achieve the objectives of the study through triangulation. In particular, the literature and policy review aimed at achieving Objective 4, on the evaluation of policy and guidance. The observation of client-provider interactions was chosen in order to achieve Objectives 1 and 4, i.e. to assess the availability and quality of care and the implementation of policies and guidance. The interviews with service users aimed to obtain data on access and demand (Objectives 2 and 3 ) and those with other stakeholders aimed principally at achieving Objective 5 , relative to the identification of the principal barriers. Although this is a qualitative study, its design draws inspiration from the Situation Analysis methodology devised by the Population Council in its "client-oriented focus on quality of care" and in its use of client-provider observations and interviews with key informants (Miller R et al. 1997).

\section{Detailed description of methods}

Key research, grey literature and policy documents were obtained by searching the Internet and from the bibliography of relevant papers. Other documents were obtained directly from the Ministry of Health and other stakeholders. Unpublished service statistics for the first 6 months of 2013 were consulted in each of the four facilities observed in the district of Dafra (see below).

Semi-structured interviews were conducted with a total of twenty stakeholders: one national representative of a FP NGO, three doctors, seven midwives, one nurse and eight service users (Tables 1 and 2). Informal meetings aimed at obtaining key information and documentation were also held at the Ministry of Health and the Ecole Nationale de Sante Publique in Ouagadougou. The health workers and the NGO representative were recruited through academic and personal networks or were approached in person during fieldwork. In order to gain as broad as possible a perspective on PPFP provision it was considered important to focus not only on providers employed by the CSPS where client-provider observations were carried out, but to include a variety of others working at different levels of the health system (including university and district hospitals) and in various capacities (e.g. in-service trainer, facility supervisor, professional school lecturer, maternity ward matron). Topics discussed pertained to what each perceived to be the main barriers to providing effective contraceptive services to postpartum women, from potential policy or legal constraints down to the concrete difficulties encountered in clinical practice (see Interview guides, Annex 5). 
Table 1: Place of work of institutional stakeholders/providers interviewed

\begin{tabular}{|l|l|}
\hline Institutional stakeholder/provider & Place of work \\
\hline 1 national FP NGO representative & Ouagadougou \\
\hline 3 Doctors & Ouagadougou university hospital (CHU) \\
\hline & Bobo-Dioulasso university hospital (CHU) \\
\hline & SOGOB - national association of gynaecologists \\
\hline 7 midwives & Ecole nationale de Sante \\
\hline & State university \\
\hline & Urban CSPS - Dafra district (Bobo-Dioulasso) \\
\hline & Urban CSPS - Dafra district (Bobo-Dioulasso) \\
\hline & District hospital (CMA) \\
\hline & Bobo-Dioulasso university hospital (CHU) \\
\hline & Bobo-Dioulasso university hospital (CHU) \\
\hline Nurse & Rural CSPS - Dafra district (Bobo-Dioulasso) \\
\hline
\end{tabular}

Table 2: Characteristics of service users interviewed

\begin{tabular}{|l|l|l|l|l|l|}
\hline Fictional name & $\begin{array}{l}\text { Reason for } \\
\text { attendance }\end{array}$ & Urban/rural & Age & Parity & Occupation \\
\hline Djeneba & PP 6th day & Urban & 23 & 2 & Housewife \\
\hline Pauline & PP 6th day & Urban & 33 & 4 & Artisan/market \\
\hline Marjam & PP 6th week & Urban & 24 & 1 & Housewife \\
\hline Josephine & ANC & Rural & 26 & 2 & Housewife/farmer \\
\hline Bibata & ANC & Rural & 20 & 2 & Housewife/farmer \\
\hline Gisele & PP 6th day & Rural & 38 & 7 & Housewife \\
\hline Diane & ANC & Rural & 19 & 0 & Housewife \\
\hline Aminata & ANC & Rural & 17 & 0 & Market \\
\hline
\end{tabular}

The service users interviewed were a convenience sample of women in late pregnancy or attending routine PN care, recruited during fieldwork in both rural and urban CSPS. They were asked questions related to their fertility intentions in the postpartum period and their opinion of and knowledge of contraception (see Interview guides, Annex 5). The conceptual framework at the basis of the interview guides for stakeholders was developed with reference to Bruce's quality of care framework for FP services (Bruce, 1990), for the women it was inspired by topics addressed in the Situation Analysis exit interview for FP clients (Miller $R$ et al. 1997). The interviews with institutional stakeholders and providers were conducted in French by the investigator, audio-recorded and subsequently transcribed by experienced research assistants. Quality-control checks were carried out by listening to excerpts and checking correspondence with the transcripts. The interviews with service users were carried out in person by the investigator (MD) with a research assistant translating, and were audio-recorded and transcribed by the investigator. 
Observations of client-provider interactions were carried out in a purposively selected sample of 2 urban CSPS and 2 rural CSPS in the Dafra district, one of the three health districts of the $2^{\text {nd }}$ largest city in the country, BoboDioulasso. The AfricSante research centre assisted in the identification of the fieldwork sites. The population covered by the centres varied between 55000 and 5000 , with urban centres serving larger populations. Three days were spent in each centre for a total of 12 days of fieldwork, and 4-6 hours of observation were carried out each day, depending on client attendance. The investigator carried out all observations accompanied by a research assistant who interpreted all communication taking place in the consultation room, most of which happened in local languages. In order to minimise positive bias in provider behaviour during observations, providers were not specifically told that the research was focused on family planning, and spending a few days in each centre probably contributed to them feeling familiar with the presence of the researchers. The investigator, who is also an experienced midwife, took detailed written field notes on the content of conversations and on the events which occurred during the consultations.

For each consultation, information was collected on the following items: demographic data (woman's age, occupation, parity, and age of children), reason for attending, and details on the consultation, with special focus on its content relative to the provision of FP advice and contraceptive methods. Writing rich field notes was deemed more useful than compiling lengthy checklists, given the rapid pace of many consultations and the limited amount of information usually exchanged. However, the choice of elements to observe was based on the Situation Analysis observation guide (Miller $\mathrm{R}$ et al. 1997). If further clarifications or information were needed, questions were asked to the provider or the woman. However, every effort was made to avoid disrupting the normal pattern of interaction and to ensure as discreet a presence as possible in the consultation room. Three IEC group sessions ("causerie educative") were also observed, and the health centres' pharmacy was visited in order to obtain information about the availability of contraceptives and accessory products, and their prices.

In total, 111 consultations were observed, including $3^{\text {rd }}$ trimester pregnancy consultations, routine PP consultations at 6 hours, 6 days and 6 weeks postpartum, and FP consultations for women more than 6 weeks postpartum. As can be seen from the breakdown of consultations by type and by health centre (Table 3 ), numbers of consultations observed in rural centres were smaller than for urban centres, because the population served by these centres is smaller, plus attendance may have been lower. For example, there happened to be no 6-week consultations in rural centres during our fieldwork. In general, 6-hour consultations were quite difficult to observe because of the small number of births taking place at each centre. However, total numbers allow for a qualitative assessment of consultations.

Table 3: Breakdown of client-provider interaction observations by consultation type and health centre

\begin{tabular}{|l|l|l|l|l|l|l|l|l|}
\hline & Pregnant & $\begin{array}{l}\text { PP 6 } \\
\text { hours }\end{array}$ & $\begin{array}{l}\text { PP 6 } \\
\text { days }\end{array}$ & $\begin{array}{l}\text { PP 6 } \\
\text { weeks }\end{array}$ & $\begin{array}{l}\text { Later } \\
\text { PPFP }\end{array}$ & Other PP & Other & TOTAL \\
\hline CSPS 1 -urban & 8 & & 6 & 10 & 14 & 2 (engorgement) & 2 (infertility) & 42 \\
\hline CSPS 2 -urban & & 5 & 5 & 3 & 24 & & & 37 \\
\hline CSPS 3 -rural & 12 & & 3 & & 4 & & & 19 \\
\hline CSPS 4 - rural & 5 & 1 & 1 & & 4 & $\begin{array}{l}\text { 1 (episiotomy } \\
\text { check-up) }\end{array}$ & & 13 \\
\hline TOTAL & 25 & 6 & 15 & 13 & 46 & 3 & 3 & 111 \\
\hline
\end{tabular}




\section{Analysis}

A thematic analysis was conducted on the transcribed interviews with institutional stakeholders and providers. A first round of free coding was done manually on the transcripts, followed by a second round of manual coding during which key themes were identified as they emerged from the texts. In the second round, an iterative process was followed between the text and the conceptual framework at the basis of the research objectives. Transcripts were then charted according to the key themes, including significant quotes. Within each theme, portions of coded text were compared and contrasted with each other so that both variety and patterns could emerge. A similar process was followed for the analysis of the women's interviews.

The more descriptive parts of the field notes from the observations of client-provider interaction were analysed through a similar process of coding, from which different themes emerged which were mainly specific to aspects of service delivery and quality of care. Without any aspiration to statistical significance, quantitative tables were also drawn up with the intention to simply summarise the recurrence of certain events such as carrying out clinical procedures, giving information on a certain contraceptive, or asking a question about obstetric history. A constellation of key themes emerging from the transcripts and observations was compiled, and logical links between them were explored. Emerging findings were repeatedly cross checked and referred back to the relevant policy documents and literature, and observations of clinical practice were compared to current national protocols and international standards of care.

\section{Ethics}

The London School of Hygiene and Tropical Medicine Ethics Committee gave ethics approval for this study, and the Ethics Committee of the Centre Muraz in Burkina Faso gave approval in the context of the parent study "Productivity, reproductive health and family planning: an inter-disciplinary study in Burkina Faso". All individuals interviewed and all women seen during the observation of client-provider interactions gave informed written consent for participation. The aim of the study and what their participation would involve was also explained verbally to women during client-provider interactions, given that many were illiterate and may not have been able to read the information sheet. The names of the health centres, and all real names of individuals involved were not retained in the analysis and will not be used in the presentation of results.

\section{Study setting}

The District of Dafra is situated within the Hauts Bassins Region in the South-West of Burkina Faso. It covers part of the city of Bobo-Dioulasso and surrounding area and has a population of 285184 , over $80 \%$ of which lives in the urban part. Within the District, there are 16 CSPS of which 9 rural, plus the District hospital (CMA) located in the city. In the Hauts Bassins Region life expectancy, female literacy and female employment are comparable to national levels. Despite the fact that the TFR and desired family size are somewhat lower than national levels (respectively 5.2 and 4.8), population growth is higher at $3.6 \%$ per year (INSD, 2008). MMR estimates are not available at regional level, however the IMR is very similar between regional and national levels. The proportions of pregnant women attending at least one antenatal care consultation, having a trained attendant at birth and having at least one postpartum consultation are similar between the regional and national levels. The median birth interval and duration of unsusceptibility are comparable to national levels (INSD, 2012).

Overall, there do not appear to be significant biases that can result from the choice of this Region or health District over any other as location for the study. The choice of this District was also motivated by the possibility of conducting fieldwork in both rural and urban settings. 


\section{Results}

This section summarises the results of the study according to the principal themes emerging from the analysis. It begins by presenting findings relative to the socio-cultural constraints on the demand for PPFP and proceeds to address the accessibility of care. This is followed by accounts of the processes which characterise service delivery, of the contraceptive methods which are available and of the quality of information provided to users. Finally, the last paragraph presents health workers' own attitude towards users.

\section{Customs, attitudes and demand}

In Burkina Faso, a woman's social status is still largely based on her childbearing ability and "some women feel shame if they walk down the road without a child on their back or without being pregnant" (accoucheuse, urban CSPS). Thus, when explaining family planning, health workers are careful to point out that birth spacing does not equate to limitation, and that women are still free to have as many children as they like: "to ask a couple to limit the number of births, that is like asking them to kill their children" (doctor, $\mathrm{CHU}$ ). Some women do not consider there that there is a choice to make on whether to continue to bear children: "Until there are still babies in your womb, you cannot stop. So it depends on God's will. For some women, the limit is 9 , for others it's 10 , for others it's more than 10. In my case, anyway, I don't think I will have the strength to have more than 10. But I can't say I'm going to stop at that, it depends on God" (Gisele, 38 years old, 7 children). Pronatalism goes hand-in-hand with fatalism: "the birds in the sky don't die, so children won't die either if that is God's will" (doctor, CHU). However, others seem to perceive that the cost/benefit ratio of a large family has been changing and that nowadays times are tougher: "when the season is good, you can get by, but when it is bad it can be difficult even to get enough food" (Aminata, 17 years old, $1^{\text {st }}$ pregnancy). Most women spoken to wanted 3-5 children and not more, for reasons including financial problems, the need to leave enough time for other wives to have children too within polygamous families, not having the strength to have more, and the difficulty to give them all an education.

All women spoken to wanted to space their births by 3-5 years so that the youngest child could gain an appropriate age: "As I'm very young, it's a bit difficult to have children very close together, so the best thing is that the child grows up a bit before having another, and also so that I can get strong again" (Aminata). Reasons quoted for wanting to space included the need to work hard in the fields, and the wish to adequately provide food and healthcare for all children in the family. Furthermore, closely spaced pregnancies are stigmatised: "if the children are too close together it brings shame both on the mother and father " (Diane, 19 years old, $1^{\text {st }}$ pregnancy). Postpartum spouse separation still persists in the Bobo-Dioulasso area: "in our family, which is large, when you give birth you move to your mother-in-law's house, and you stay there until your child walks or is 2 years old, before you go back to live with your husband. Before that you are not allowed to go back to your husband's house" (Diane). Within polygamous families, although spouse separation enables spacing, rivalry may mean that the first wife may want another child "in order to show the younger wife that the husband still wants her, and that she can still get pregnant" (accoucheuse, rural CSPS). During one consultation, a woman confided: "I was going to stop contraception because there is a new wife, but my husband wants me to continue using it, so in the end I agreed" (39 years old, 4 children).

Informants interviewed report that spouse separation is disappearing in the cities, however postpartum abstinence is still highly valued. Even women who stay with their husbands still aspire to delaying the resumption of sex, or at least express conflicting views. They feel the influence of traditional morality, but within postpartum cohabitation, with no co-spouse, they also perceive they have no power to negotiate the resumption of sexual relations with their husband: "If it depended on me, even if I waited 2 years, there would be no problem. But for him it's different. When he feels the desire, when he wants to have sex, if you refuse, he could force you, so I 
can't say exactly what day I will start, when my husband's desire arises, that will be ok" (Gisele). Furthermore, couples may not be used to talking openly about such issues: "There is a communication, not too much, but it's ok. As we are farmers, the men don't really sit down much to chat with their wives" (Aminata). Thus, a cohabiting woman may actually be unwilling to adopt a method, because "if someone sees her doing contraception before her child is a certain age, they will know that she is having sex" (midwife, $\mathrm{CHU}$ ).

Modern methods appear to be still viewed with suspicion by many people, and common rumours include the possibility that modern methods can cause anything from twins, cesareans, malformations to cancer. In the postpartum, women worry that pills or condoms (as well as sex itself) can make the child fall ill. A young woman interviewed asked whether the implant could make her sterile, and the IUD is feared because it can pierce the abdomen or provoke abortions. The general perception is that pregnancy can't occur before 6 months. Several women spoken to at the health centre were aware that they could become pregnant before seeing their periods, however one explained that this could occur straight after birth because "the "debris" in your body means that it's not clean yet" (Diane). Women using methods which cause amenorrhea worry about being pregnant or that blood is collecting in their abdomen. Modern methods are reportedly blamed for any other health problems which may arise. According to one stakeholder, "even educated people think and act exactly like illiterate people... On contraception, no one knows exactly what it is, but everybody thinks they know" (midwife, state university).

The general perception is that men are opposed to family planning, in some cases because they fear that it would allow their wives to be unfaithful. Thus, even for women who are convinced that they want to use contraception, obtaining their husband's agreement may constitute a major hurdle. A combination of threats will usually dissuade a woman from going against her husband's will: "I married you to have children, if you don't want to have them l'll marry another woman who will give me some" (doctor, $\mathrm{CHU}$ ). Other women will adopt a method, but in secret: "often when husbands realize that we use something they don't agree, I myself had to conceal my use from my husband between the $5^{\text {th }}$ and the $6^{\text {th }}$ child" (Gisele). Many providers reported that women sometimes come to the health centre at night so they won't be seen. On one occasion observed during fieldwork, a FP hand-held record was found on the ground, and staff were concerned about keeping it safe so that it wouldn't fall into the hands of other villagers, with the possibility of the woman's husband being informed. The discreet nature of the injectables appears to be part of the reason behind their immense popularity. Stories abound of women being disowned, or returning to have the implant or IUD removed because their husband's reaction to discovering it was: "either you get it removed, or you're going to leave my house" (midwife, urban CSPS). As one provider put it, "even if we explain everything, including side effects, if your husband tells you to come and have it removed, what are you going to do? You come and have it removed! Because in our region the woman will never speak her own mind, it's always the man who is in command and thinks he's the boss" (midwife, urban CSPS).

\section{Financial and geographical accessibility}

This power imbalance, in combination with some women's lack of financial independence, make services less accessible. PP women often come to the $6^{\text {th }}$ week appointment without enough money to pay for a method because they have been reluctant to discuss contraception with their husband, or to ask him for money for something he is unlikely to perceive as urgent. Often these dynamics mean a woman may have to forgo her first choice of method: "if I want the implant, I have to pay 800CFA, plus I have to pay the taxi which will be 300CFA, so my husband has to give me minimum 1200CFA, and it's not easy to get that amount of money from my husband" (midwife, urban CSPS). 


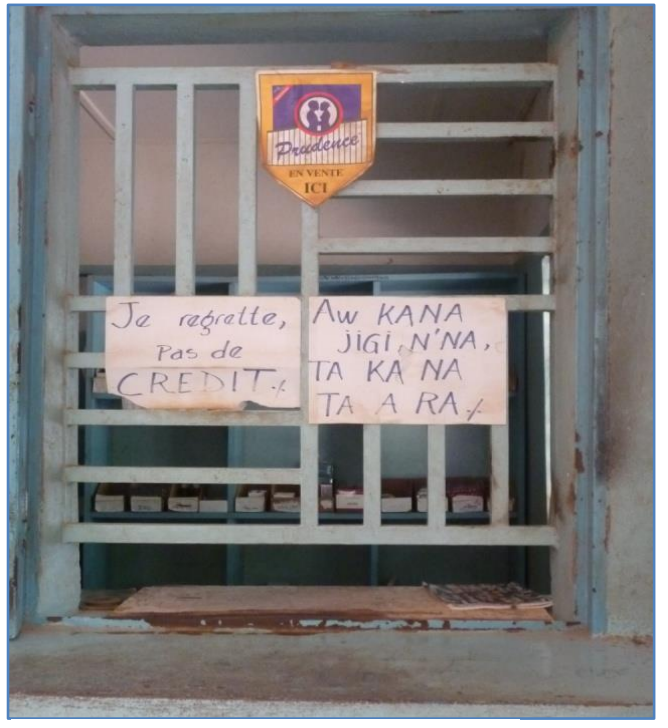

Figure 1: Pharmacy, rural CSPS
Aside from the price of contraceptives themselves, women were also observed being asked to pay for the products needed to remove implants, and one 43 year-old woman with 11 children and a 6 -month baby was asked to return again because she didn't have enough money (800 CFA) for the speculum needed for an IUD check-up. When subsidised "accessory" products are finished, women have to pay. Thus, women were observed being asked to pay for gloves in three out of the four centres visited, and pregnant women were seen turned away from routine ANC appointments because they hadn't brought any money. In two out of four centres there were no FP cards and ANC booklets (normally free), so in one centre women were being asked to pay for the standard health booklet (at $150 \mathrm{CFA}$ ), and in the other their health information was being given out on slips of exercise book paper.

The need to exclude pregnancy makes access even harder for the many still amenorrheic women who seek contraception later than the scheduled $6^{\text {th }}$ week appointment, because of the high cost of pregnancy tests (varying between 650 and 1500 in "the accoucheuse's own stock"), coupled with the fact they are often out of stock in some centres. Thus, many women are either requested to return with the right cash, or, as is very frequently the case, they are prescribed a high-dose course of the combined pill and told to return with a withdrawal bleed. The fact that they cannot obtain their chosen method right away can demotivate women, and some were observed being confused and distressed at the idea of having to take pills for some time.

The cost of products must be added to any costs, both financial and in terms of work lost and time spent, related to physically reaching the health facility. Living $10-15 \mathrm{~km}$ away can be a barrier to attending even routine AN and PP appointments at the local CSPS if there is no evident health problem to solve. In the villages, women are in charge of the household and farming, so they are reluctant to lose a day's work in order to visit the health centre. Thus, asking a woman to return another time because she didn't have enough money is particularly problematic in this context, because she may decide that she can't afford the costs of a second trip. In the case of referral for methods which aren't available locally (such as LARC in rural areas, see below) transport costs, more or less foreseeable expenses related to staying in town, having to get her husband to accompany her and having to be away from her children for a whole day will almost certainly prevent her from going.

\section{The process of PPFP service provision}

The principal avenue for PPFP care provision is routine PP care, which is based upon 3 main consultations: at 6 hours, 6 days and 6 weeks (Ministry of health, $2010 \mathrm{c}$ ). However, many women are lost to the system once they leave the facility after birth: "There are many who don't even come on the $6^{\text {th }}$ day. They give birth and we never see them again. Especially what with the work in the fields, and especially now with in the winter, they stay in the bush. They say yes, we hear you, but do you think we have the time to come?" (nurse, rural CSPS). Thus, whereas the 6-hour appointment is almost universally attended because it occurs before women are discharged from the facility, just over half of women attend the $6^{\text {th }}$ day appointment, and only a third or less attend on the $42^{\text {nd }}$ day (Dafra district service statistics, 2013). Among those who attend, few exit with a contraceptive method. During the observations conducted for this study, no women left the $6^{\text {th }}$ hour or $6^{\text {th }}$ day consultation with a method or a prescription for a method, and among the few women who attended the $42^{\text {nd }}$ day visit, only about half of them did. 
Although, according to the PNC guideline, women should receive FP advice throughout the postpartum period (Ministry of health, $2010 \mathrm{C}$ ), in practice, providers focus on the $6^{\text {th }}$ week: "when they come on the $6^{\text {th }}$ day, we say to return at $6^{\text {th }}$ week and there it's compulsory, all women must get their counselling and then they can choose what they want" (midwife, $\mathrm{CHU}$ ). When mentioned at the $6^{\text {th }}$ day consultation, the woman is often told to start thinking about contraception so that when she returns at 6 weeks she can choose a method. During the observations, the topic was mentioned during about half of the $6^{\text {th }}$ hour and $6^{\text {th }}$ day consultations, apparently depending on the individual provider. At the $6^{\text {th }}$ week visit almost all women are asked if they wish to start a method and what is their choice. However, because they are not all warned, several are not aware that a choice was supposed to be made. Actual counselling on methods available rarely takes place in advance of the $6^{\text {th }}$ week appointment. If a woman has already chosen a method at that point, she is often not told what other methods are available, thus she may never receive the broader counselling on contraception which is explicitly provided for by the FP guidelines (Ministry of Health, 2010 b). No FP message was passed on to postpartum women attending outside the calendar of scheduled visits because of particular problems (episiotomy check-up, engorgement).

If a woman doesn't want to adopt any method at 6 weeks, unless she spontaneously mentions a cost problem or lack of consent by her husband, no attempt is made to understand the reasons for her refusal, and whether this is consistent with her reproductive intentions or life circumstances (e.g. spouse separation). The provider often warns her that if she leaves and then returns for a method at more than 2 months postpartum, she will have to be examined or have a pregnancy test done, however no steps are taken to encourage or facilitate her return, and there is no discussion of when the appropriate time to return would be, given her personal situation.

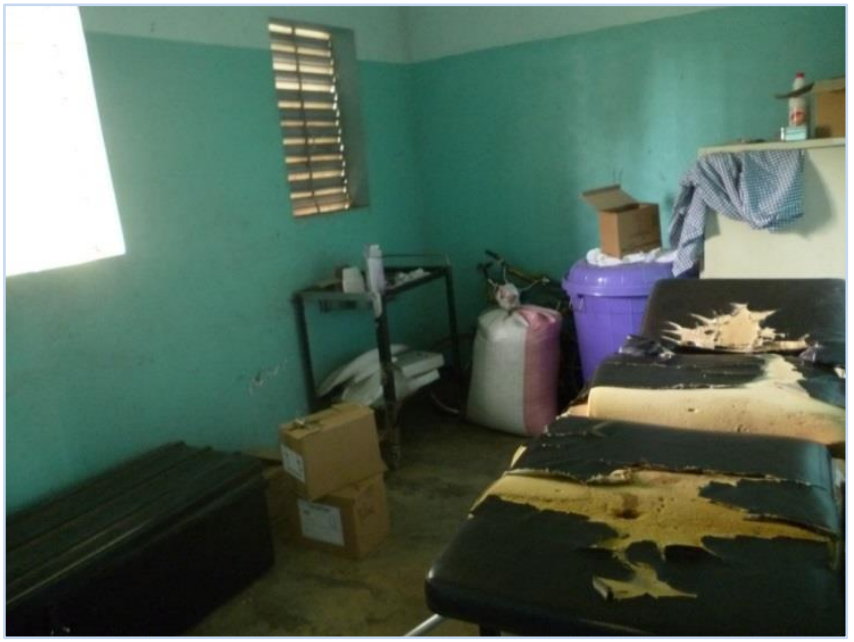

Figure 2: Consultation room, rural CSPS
The national antenatal care guideline, which draws strongly on the continuum of care concept (WHO, 2005), also mentions FP among topics which should be discussed (Ministry of Health, $2010 \mathrm{c}$ ). Many providers recognise that a discussion of the woman's future reproductive intentions should come up naturally at antenatal consultations, "because you need to ask the woman the age between the children". However, "theory and practice are 2 different things" (midwife, urban CSPS). In the discussion on birth preparedness, they say, "we talk about transport, place of birth, companion and financial preparedness, there isn't anything on FP or

breast feeding": "talking about FP during ANC doesn't really come into our minds" (midwife, state university). On the whole, during our observations of ANC consultations in the third trimester, FP was never brought up or discussed. Birth preparedness seems to be given more prominence in rural centres, where providers were understandably keen to stress the importance of facility delivery, however no discussion related to the postpartum period was ever observed.

At whichever point FP happens to be discussed, this is rarely a full consultation which includes a holistic assessment of the woman's reproductive intentions, contraceptive needs and personal circumstances. The woman's immediate request is addressed, but this is not usually contextualised within her obstetric, gynaecological and contraceptive history. In the case of visits for repeat prescriptions, this information is not readily available on the woman's hand-held card, and providers do not have quick access to previous entries on the register concerning past visits by the same woman. It is not routine to ask again, and all that is documented on the register is whether or not this is a change of methods. 


\section{Availability of methods}

For those who do wish to begin contraception at the $6^{\text {th }}$ week visit, the range of methods available is fairly limited. Male and, in some centres, female condoms are available from the pharmacy, but never provided or discussed during consultations. Several institutional stakeholders and providers are supporters of Long Acting Reversible Contraception (LARC), which don't rely on women's memory and literacy. Indeed, women themselves often express reluctance to take oral contraceptives because they claim they will forget pills, and frequently miss appointments for the injectables because they are unable to read the date on the FP card. However, only nurses and midwives are allowed to provide LARCs, whereas accoucheuses auxiliaires are not (Ministry of Health, 2010 b). Thus, because there are virtually no midwives or specially trained nurses in rural areas, these methods are effectively not available outside cities.

Thus, leaving condoms aside, the range of methods available for women to choose from differs somewhat between urban and rural areas. In the urban CSPSs essentially four methods are made available during consultations: the most common is the injectable, followed by the pill, the implant, and the IUD. However, service statistics for 2013 reveal that the number of new implant users surpasses that of new pill users, except during April and May, when there was a shortage of implants (Dafra district service statistics, 2013). In relation to stock issues, stakeholders report that "almost all services have this problem at some point. If the method you want is not there and you get offered a method that you don't want that is very demotivating!" (midwife, state university).

In the rural CSPSs, instead, there are essentially two options: the injectable and the pill, the first being the most popular. However, for women in the first 6 months postpartum, the only available method is actually the injectables, because progestogen-only pills are not stocked. In fact, uptake in this period is rare given that routine PNC attendance is so low. Providers acknowledge that once a woman leaves the facility "you won't see her, she lives behind the hill, it has been raining, there is no road, she won't come back" (doctor, $\mathrm{CHU}$ ). A strategy providing a contraceptive method before the woman leaves the facility is not feasible, because IUDs are not available, nor can providers prescribe pills to be started at 6 weeks (on the Lactational Amenorrhea Method, see below).

Even in the urban centres, the number of new IUD users per month ranges from 0 to 5 (even though 90-100 women give birth at each centre every month). This illustrates how even where providers have a professional title which would allow them to provide this method, they may still lack skills. There is universal recognition among stakeholders that current pre-service education is unable to train midwives to a level where they are confident in providing the full range of contraceptives. The curriculum was recently re-written in collaboration with the Ministry of Health to improve the mix of theoretical and practical FP training (Ministry of Health et al, 2012). However, implementation of programmes is increasingly difficult because class sizes now reach up to 200 students, and a generation of teachers is reported to be retiring. Despite doing a total of 4 months FP practical placement, a high ratio of students per facility means most don't get the chance to practise IUD insertion on real women: "it's not the same if you are supervising 5 or 10 students during a morning; if you have 5 they'll all get to do something, if you have 10 it's not so sure" (midwife, $\mathrm{CHU}$ ). This may translate into a reluctance to provide information about the method: supervisors and in-service trainers report that providers consistently downplay the benefits and overstate the side effects of the IUD, because they lack confidence in insertion.

Once qualified, opportunities for in-service training depend on the availability of courses organised by the District employing them, and on being chosen to attend by service managers (Ministry of Health $2012 \mathrm{c}$ ). However, training alone may not be sufficient. In one centre, recent graduates of a LARC update had started placing and removing implants, but not IUDs, because "it's a bit complicated" (midwife, urban CSPS): even if the quality of courses is excellent, there may still be problems related to the level of support and supervision necessary to put into practice what has been learnt, once back in service. 


\section{Availability of information}

All women interviewed had knowledge of at least 3 methods among the injectables, the implant, the pill, the IUD and condoms. The CSPS itself featured strongly as a source of information, and curiosity to learn about new methods emerged, especially from younger women. However, providers only provide information about methods which are popular and readily available. In urban centres, the methods mentioned during consultations are almost exclusively the injectable, the pill, the implant and the IUD. Only on one occasion was an accoucheuse observed using an illustrated chart to explain a broader range of methods during an individual consultation. In three of the four centres studied, the "causerie educative", an informal ten-minute talk given by a health worker in front of the audience of women before the start of AN/PN/FP consultations, is another occasion during which information on FP is provided. However, FP has to compete with a variety of other topics, among which PMTCT appears to play a major role. During twelve days of fieldwork it was possible to observe two causeries dedicated to FP, however these were general discussions on the advantages of birth spacing, and women were told that the explanation of the methods would happen next time. The causeries have no official government programme, but a UNFPA picture flipchart was used. However, even an exhaustive causerie can be no substitute for individual counselling. Furthermore, an individual woman may arrive late, and there is no guarantee that FP methods will be explained on the day she happens to attend.

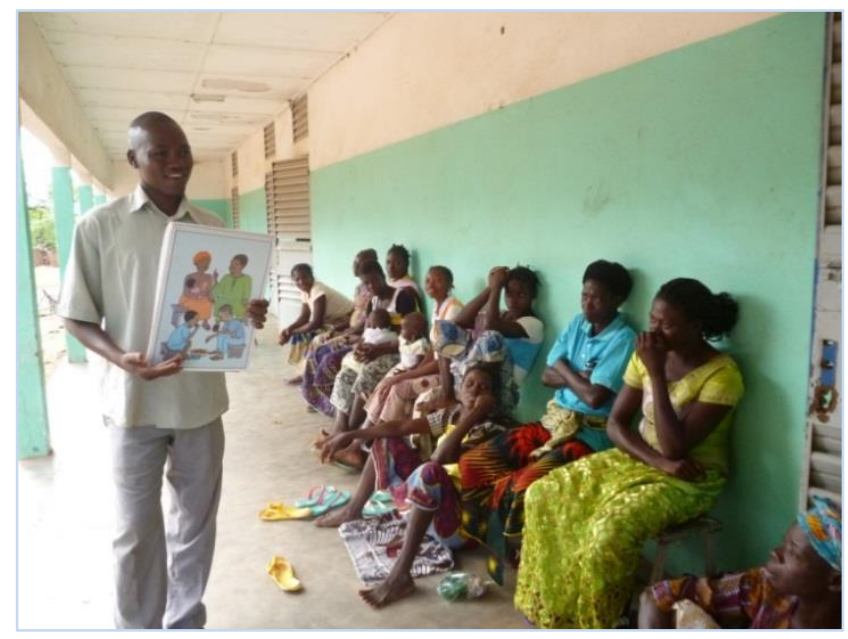

Figure 3: Causerie educative on family planning, rural CSPS

In many cases, specific methods are not promoted because of reported lack of demand. Thus, for the female condom there are "too many protocols, too complicated, too big, girls don't like it" (midwife, state university): one rural centre's response to this has been to simply stop ordering them. Similarly, promoting the male condom is considered to be pointless because the husband's agreement is necessary, and this is impossible to obtain because condoms are reportedly only accepted during casual encounters and for STI prevention. However, this failure to publicise less popular methods can itself lead to a reduction in the range available. In one rural centre, even though a LARC-trained member of staff worked there, they had stopped ordering implants once the first stock expired: "women didn't want them, they love Depo and pills" (nurse, rural CSPS).

On other occasions, the information given is not impartial because it is influenced by the provider's own opinions, personal experience or religious opposition to certain methods. One example is the insistence that women choosing the implant commit to keeping it in for at least 3 years because "it's a waste of the State's money as it is a subsidized product" (accoucheuse, urban CSPS). For the IUD, one provider doesn't talk about it because he believes it is unsuitable for village women because of their lack of personal hygiene (nurse, rural CSPS).

The case of the Lactational Amenorrhea Method (LAM) is the most typical example where a cultural smokescreen is used to mask providers' own scepticism about a method. Providers who are familiar with it are reluctant to discuss it because they are aware that it only provides protection for 6 months and that exclusive breastfeeding is not part of local culture. One woman, advised to exclusively breastfeed, replied to the male nurse: "You would not look as you look now, if you had only been given breast milk!" (PP mother, rural CSPS). Providers also realise that within families, women often lack the decision-making power necessary for adherence: "when the mothers 
leave to go into town, there are the old women there who are waiting to give the babies their infusions" (doctor, $\mathrm{CHU}$ ). They report that "breastfeeding is universal, but always combined with water, infusions, boiled concoctions. The baby gets washed, made to drink and purged" (midwife, state university). On the one hand, some providers don't take LAM seriously as a method, and think that specific actions aimed at promoting it are unnecessary: "when you see them come at 1 year or 8 months amenhorreic, that's LAM working for you! They use it without knowing it" (midwife, $\mathrm{CHU}$ ). On the other hand, others depict the method as too technically demanding, reporting that health workers are not trained to promote it and that women don't have a sufficient level of education to adhere. Confusion and scepticism about LAM result in the fact that it is never mentioned to postpartum women. Thus, despite the fact that virtually all are told and many are aware that they should exclusively breastfeed for 6 months for the sake of their child, the potential fertility-reducing effect of exclusive breastfeeding are never explained and none of the women interviewed had any knowledge of it.

Once a method is chosen, the woman is usually told about potential side effects such as spotting or amenhorrea, although some disadvantages are never discussed (eg. lack of protection against STIs/HIV for hormonal contraception). However, if a woman comes having already decided what method she wants, providers hardly ever provide information about other options she may not be aware of. Even in the case of a repeat user, the provider cannot know if she was ever counselled on all methods, because this is not specifically documented anywhere. On the one hand, providers complain that women "don't give you time to talk through all the methods, they request a certain one because that is what their friend or neighbour wanted, regardless of what would be best for her... They always come with an idea already in their head" (doctor, CHU). On the other hand, they report that it is not their place to interfere: "even if we think her choice of method is not appropriate we don't have the right to influence her choice" (midwife, state university).

\section{Providers' perception of cultural barriers}

Whilst providing lip service to the rhetoric of informed choice, many providers actually appear not to trust women as being capable or deserving of this right. At times, they portray women as victims of conservative social norms, putting up stoically with the brunt of continuous childbearing: "they may complain of their lack of decision-making power, or other things, but despite all their suffering no woman complains of the number of children" (midwife, urban CSPS). This approach finds its way into "defensive" advice which is sometimes given on contraception, for example in relation to the perception of men's de facto control over the resumption of sex: "it's best to protect yourself while you wait for the other to decide, because very frequently someone else is deciding for you!" (midwife, $\mathrm{CHU}$ ). Others see women themselves as bearers and expression of traditional culture and attitudes, and report that they are ignorant, unable to retain information, and unwilling to listen. Women themselves are blamed for not attending: "even just behind the District hospital there are people who don't come for contraception", and "it's not always the husband stopping them, they themselves don't even perceive the need to seek FP. I just met a woman whose oldest daughter has 2 children, yet she herself is still having children. It's too much!" (midwife, district hospital).

The same ambivalent attitude towards the possibility of equipping women with the means to make informed choices applies to the possibility of involving men. There is universal agreement among institutional stakeholders that if men attended the consultations with their wives, this would significantly improve the uptake of contraception, and providers are aware that the policy encourages this (Ministry of Health, 2010 a). One midwife told that recently the husband of a woman who had a stillbirth was successfully counselled and persuaded of the benefit of his wife having an implant placed straight after the birth, so her body could recover. Others believe that if given the right information, men's authority could be harnessed to discourage unhealthy traditional practices: "if the husband doesn't agree, nobody will purge his baby; if his own mother is there and he says not to purge it, she will not do it" (midwife, state university). One woman even recounted how her husband changed his attitude towards contraception when she herself gave him correct information: "Last time I explained it to him, 
and he didn't accept. I insisted, and he didn't accept. So that's why I decided to have it done behind his back.(...) This time when I ask him he is not going to refuse, because it depends how you talk to him about it. If you say you want to do contraception because you don't want to have any more babies, he won't accept that. But if you explain that you want to do it so that you can regain strength, so that the child can really gain an appropriate age before you get pregnant again, he will understand. So you need to really explain well" (Gisele).

However, most providers are convinced that involving men is an uphill struggle because they are fundamentally opposed or uninterested in FP. As a result, they make no effort to include them. According to one provider, the law stopped requiring husbands to come to FP consultations with their wives because they refused to come, and were giving their wives their own ID cards to take, instead of going in person: "men don't like to go to a place where one talks about issues to do with women down there" (midwife, district hospital). During our observations, there were only two occasions when the husband entered the consultation room with his wife. One of the men was asked to leave straight away, and the other was allowed to stay, but only for as long as he was required to translate for his wife. On the $6^{\text {th }}$ day postpartum consultation, women are told to go home and discuss the possibility of starting a method with their husbands, but they are never actually encouraged to bring their husbands along to the $6^{\text {th }}$ week appointment. 


\section{Discussion}

\section{Summary of results}

From the point of view of supply (Objective 1), this study reveals substantial gaps in the availability of quality PPFP services in primary care centres. No discussions on postpartum preparation PPFP or breastfeeding take place during individual ANC consultations. In the postpartum, the quality of FP counseling is also unreliable and appears to depend largely on the individual provider. FP is not always mentioned at the $6^{\text {th }}$ hour and $6^{\text {th }}$ day appointments. Women are offered contraception at the $6^{\text {th }}$ week appointment, however many are not prepared to adopt a method: they are either unaware that a choice was supposed to have been made, or they were not properly counseled during any previous contact, or they haven't brought enough money. At whatever point they occur, consultations don't usually take the woman's contraceptive history or life circumstances into account in order to encourage the most appropriate choice of method and discuss the optimal timing of adoption. Women are not always informed about the full range of methods available or told about side effects, partly because of providers' own biases, and no effort is made to encourage men to attend consultations. Providers' attitude towards the possibility of adequately informing women and involving men is ambivalent and largely resigned. The range of methods actually available is limited, due to the following factors: stock issues, provider reluctance to publicize and provide certain methods, lack of skills, and the fact that current policy prevents accoucheuses from providing LARC.

As far as access is concerned (Objective 2), women face geographical barriers in accessing PN care after discharge from the facility after birth, thus routine appointments at 6 days and 6 weeks postpartum are poorly attended. Referrals to obtain a method that is not available locally are difficult to arrange. The cost of products is a barrier and the exemption policy for consumables (for the insertion and removal of implants and IUDs) is not fully implemented. Apart from routine PN care, other occasions along the continuum of care are wasted during which FP advice and counselling could be provided, including routine ANC. Amenorrheic women demanding contraception after six weeks postpartum face specific hurdles, such as the price of a pregnancy test or the requirement to stimulate a withdrawal bleed.

The demand and uptake of PPFP (Objective 3 ) are generally low. Although birth spacing is valued, large desired family size may still play a role in determining low demand. Furthermore, the persistence of specific customs and social norms such as spouse separation and postpartum abstinence still have an impact on uptake, especially in rural areas. The opposition of men to contraception emerges as a strong theme. Lack of information and rumours also contribute to giving modern contraception a bad reputation.

Significant policy barriers (e.g. in relation to user costs and accoucheuse authorisation to provide LARCs) exist in relation to the provision of PPFP (Objective 4 ). The appropriateness of current policies and guidelines will be discussed below as part of the sub-headings relative to supply, access and demand. The results of this study show that although there is room for improvement in policies and guidelines, there is already a significant gap between theory and practice.

In the following sections, some of the most significant barriers to meeting unmet need for FP in the postpartum will be discussed in relation to supply, access and demand and followed by recommendations for potential areas where improvements could be made (Objective 5). 


\section{Supply}

From the point of view of quality of care, many of these findings confirm what emerges from a recent study conducted in Ouagadougou, which also included observations of client-provider interactions in primary care centres (Rossier et al. 2013). Both studies identified the failure to adequately counsel women, provide complete information on contraceptive methods and tailor advice to individual needs as significant concerns for quality. This study's findings concerning the failure to accurately and consistently explain side effects are also consistent with DHS data, which show side effects to be the most common reason for method discontinuation, following the desire for a pregnancy (INSD, 2012). The failure to inform women about methods other than their first choice may in fact contribute to un-quantified levels of abandonment of contraception altogether, because women may not be aware of alternatives.

This study contributes a new perspective on provider attitude. Good interpersonal relations and the provision of accurate and exhaustive information have long been recognised as key elements in the quality of FP care (Bruce, 1990), and constitute reproductive rights enshrined in national law (Assemblee Nationale, 2005). However, health workers appear to oscillate between seeing women either as perfectly informed, but illintentioned agents, who somehow bring their own misfortune upon themselves and thus cannot be interfered with, or as people who are so ignorant and backward that engaging with them would be pointless. Despite the fact that women (and men) are largely well-disposed towards measures which can improve their lives and health, and those of their families, they are not essentially trusted as individuals who can make informed choices.

Some of the clinical guidelines available to providers are adequate, whereas others lack sufficient detail on PPFP provision. The general FP guideline (not limited to PPFP) provides sufficient detail on counselling (Ministry of Health, 2010 b), whereas there is room for improvement in the PNC guidelines (Ministry of Health $2010 \mathrm{c}$ ). The latter could place more emphasis on FP counseling at the $6^{\text {th }}$ hour consultation, and could be more explicit in requiring health workers to systematically provide comprehensive counseling on FP at the $6^{\text {th }}$ day appointment. Given the failure to fully implement existing guidelines, further training and supervision of providers may be needed to be improved to improve adherence. A comprehensive supervision tool has been developed by the Ministry of Health, which has the potential to improve practice (Ministry of Health, $2010 \mathrm{~d}$ ). However, a change in service culture is also needed, within which the user is acknowledged as an active participant in the health care process. An individualised approach, which takes the likelihood of careseeking in the postpartum and the likely duration of unsusceptibility into account, would be particularly useful in a context of low attendance, where each contact occasion should be utilised to the full.

Restrictions in the availability of methods or information on methods due to a variety of staff biases have been documented in the international literature (Bulatao et al. 1989, Campbell et al. 2006). In this study, the failure to promote methods which are not available onsite may be due to providers' awareness that these are more expensive or that a referral is unlikely to be feasible. However, general perceived lack of demand was observed to actually prevent the stocking of certain methods. Thus, providers appear to be trapped in a chicken-and-egg situation whereby lack of demand is blamed for the lack of popularity of a method, and as a result no information is provided about it, making an increase in demand unlikely.

The stock problem described in this study is apparently not an isolated case, despite government initiatives over the past ten years (Ministry of Health, 2005 and 2009 a). Most recently, this has been addressed through the adoption of specific measures aimed at improving the collection and management of stock utilisation data (Ministry of Health, 2012). Preventing these problems is key because failure to obtain a desired method can discourage adoption and increase the likelihood of discontinuation (Pariani et al. 1991).

Although a FP service which is "skewed" towards particular methods is by no means an exclusive feature of Burkina Faso (Sullivan et al. 2006), the availability of a good range of methods means that individual needs are 
more likely to be met whilst minimising the health risks associated with a less-than-ideal option (WHO, 2010). The broader the range, the greater the chance that a woman can switch to another method if required (Cleland et al. 2006). In rural centres, the de facto availability of only one method in the first 6 months postpartum, coupled with very low PNC attendance, is a clue to the fact that giving any contraceptive method to a woman in the first few months after childbirth is a fairly rare event. If more women are to adopt, efforts should be made to increase the number of methods available (Ross J et al. 2002).

LARC appears to be particularly cost-effective in terms of number of pregnancies prevented (Chiou et al. 2003) and has low failure rates (Hubacher et al. 2008). Furthermore, discontinuation is probably less likely, as it requires health worker input. The lack of availability of these methods seriously limits options for women who have completed their families or those who want to significantly postpone any future childbearing. However, current FP policy relies heavily on the midwife, a professional figure that not exist outside cities (Ministry of Health, 2011a). Paradoxically, in rural areas, less trained health workers conduct the bulk of maternal care (INSD, 2012) and take on far more serious responsibilities than providing LARC. Despite having abandoned the training of accoucheuses in favour of midwives, it will still take several years for there to be sufficient numbers of midwives to staff all rural CSPSs (Ministry of Health 2012 b). Furthermore, there are already serious constraints on the ability of schools to train the increased number of student midwives to sufficient standards (Ministry of Health, 2009 b). A policy change enabling accoucheuses to be trained to place implants and IUDs would provide a temporary solution. The WHO recommends that "auxiliary nurse/midwives" place IUDs and implants (the latter, with targeted monitoring and evaluation) (World Health Organization, 2012), and task-shifting for the provision of LARC has proven safe in other settings (Vernon, 2009; Affandi et al.1987, Eren et al. 1983).

Within contexts with high levels of unsusceptibility, the rationale for a "double protection" strategy has been contested (Brown, 2006), and it has even been argued that it could be counterproductive in contexts with high levels of method discontinuation (Becker and Ahmed, 2001). This study confirms Rossier and Hellen's (2013) finding that LAM is never discussed and breastfeeding advice is given only for the baby's benefit, despite the fact that reproductive health policy does mention its role for birth spacing (Ministry of Health, $2010 \mathrm{a}$ ). It is likely that women's lack of awareness of the fertility-limiting potential of breastfeeding, which also confirms Rossier and Hellen's findings (2013), is due to the fact that breastfeeding and sex itself are considered to be fundamentally incompatible by traditional culture, and sex only used to be resumed once the baby was weaned (Taverne, 2000). Currently, women practice an" incorrect" version of LAM: breastfeeding is rarely exclusive (INSD, 2012), but women manage to remain amenorrheic because they are never separated from their babies and feed frequently for many months (Bonnet, 1988). In any case, development and urbanisation are likely to disrupt these patterns and shorten unsusceptibility. Thus, the teaching of LAM has a place among other methods and will be suitable for some individuals, especially those who can be relied upon to return at 6 months to choose another method, as already provided for by the FP guideline (Ministry of Health, $2010 \mathrm{~b}$ ).

\section{Access}

Along the continuum of care, postpartum check-ups are only one of the occasions during which FP can be addressed. Most notably, FP counselling during ANC, as part of the promotion of postpartum preparedness, could reach many more women, given that ANC is much better attended than PNC (Dafra district service statistics, 2013, and INSD, 2012). Evidence for the effectiveness of antenatal counselling on contraceptive use in the postpartum has been mixed (Smith et al. 2002, Barber, 2007), however, most recently, a randomised trial in Nigeria has shown a significant increase (Adanikin et al. 2013). In Burkina Faso, given that lack of preparedness is the main reason for the failure to commence contraception at scheduled PN appointments, there is likely to be considerable untapped potential in starting to pass on the message at a much earlier stage. The ANC guideline mentions family planning and breastfeeding among topics to be discussed at consultations, however there is no 
requirement in any national guidelines for comprehensively or systematically addressing postpartum preparation or drawing up a postpartum plan (Ministry of Health, $2010 \mathrm{c}$ and d). Further steps could be taken to improve the pregnancy health booklet in order to prompt providers to address FP (for example, through a checklist of topics) and possibly record a plan for PPFP.

Women who don't adopt a method during routine PNC may return later, when they resume sexual relations, however levels of unmet need suggest that many fail to do so. Thus, the failure to encourage or facilitate the return of these women is a serious fault in the system. Reluctance to provide contraception to amenhorreic women is common and has been reported in Burkina Faso and elsewhere (Rossier and Hellen, 2013, Campbell et al. 2006). In this study, the practice of provoking a withdrawal bleed through COC pill administration emerged as ubiquitous, despite the fact that this practice is not supported by either national nor international guidance (Ministry of Health, 2010 b; WHO, 2004). Given that in most cases the WHO checklist or a clinical exam can exclude pregnancy with reasonable certitude (WHO 2011), providers should be made aware of these recommendations and may need training updates. Crucially, advocacy is also needed to ensure that pregnancy tests are free and readily available when required.

The principal access barriers to contraceptive services emerging from this study, such as geography, cost, and getting permission from family members, have been abundantly described in the literature (Campbell et al. 2006; Cleland et al. 2006) and a majority of women is affected in Burkina Faso (INSD, 2012). Other studies and reports confirm that the costs of contraceptives, accessory products and pregnancy tests is a particularly significant barrier in the country (Amnesty International, 2009; Rossier and Hellen, 2013; Rossier et al. 2013). Although contraceptives are subsidised, fees are not waived for the poorest women, as they are for normal birth and obstetric complications (Ministry of Health, 2006). This absurd situation persists, despite the fact that it is lack of contraception itself which can lead these women to have high risk births. The extent to which there is evidence that the elimination of user fees can raise demand for contraception has been called into question (Matheny, 2004), and challenges related to the implementation of such strategies have been noted (Ridde and Morestin, 2011). However the effect of such a measure may well be amplified in this context, where cost and geographical barriers are often combined (e.g. needing to go home and return with more money). Efforts aimed at enforcing existing regulations on pricing are also needed. For example, this study reveals that the 2011 Directive which relieves women of the cost of the accessory products necessary for LARM insertion (e.g. gloves, speculum, Bethadine, swabs) is not yet implemented throughout the country (Ministry of Health, $2011 \mathrm{~b}$ ).

\section{Demand}

The low level of attendance at routine PNC appointments observed in this study is in line with DHS data, which indicate that only a third of women attend PNC more than 24 hours after delivery (INSD, 2012) and the low uptake of contraception at this time confirms Rossier and Hellen (2013)'s findings.

This study attempts to shed some light on the complex ways in which traditional customs and social norms influence the uptake of PPFP. For example, although polygamy may promote healthy birth intervals through spouse separation, it may also discourage women from committing to limiting their childbearing and adopting longer-lasting contraceptive methods. Women's ambivalence towards the resumption of sex may itself be driven by the wish to adhere to the moral value of sexual restraint (Johnson Hanks, 2002), but may also be reinforced, for some, by traditional beliefs such as the fear that sperm will alter the milk and harm the baby (Rossier and Hellen, 2013, Alfieri and Taverne, 2000). Even with the decline of spouse separation, stigma against postpartum sex may prevent women from seeking contraception early and lead them to dismiss routine invitations to start a method during PN care. Thus, within new patterns of cohabitation, coupled with scarce negotiating power and 
bad communication between spouses, these attitudes can put women at risk of resuming sexual relations earlier than planned, in line with Rossier and Hellen's (2013) findings.

This study confirms the results of other research conducted in similar settings in identifying traditional morality and religion (Dehne, 2003), lack of knowledge on the body and fertility (Rossier et al. 2013), and fear of side effects, including of infertility (Williamson, 2009) as factors which may limit demand for modern contraception. Having to request permission or money from the husband is indicative of a power imbalance within the couple, even though this may be less marked among the Bobo and Zara in the Bobo-Dioulasso area, among whom it is common for women work outside the home and have disposable income (Alfieri, 2000).

The failure to involve men or request their presence observed during this study confirms the findings by Rossier et al. (2013). Although men and women often have discordant fertility desires (Becker, 1999), this study would lend support to the view that it is often adherence to gender roles and lack of communication which are at the origin of the couple's disagreement on whether to adopt contraception (Mason and Smith, 2000). This implies that there is likely to be real potential in informing and involving men and that ways to do so should be explored.

The axiom of high desired family size itself deserves to be called into question. Although most pregnancies are wanted in retrospect, the extent to which any pregnancy is rationally planned and perfectly timed has been the subject of ongoing debates (Santelli et al. 2003, Trussell et al. 1999). In a critique of the concept of unmet need, Speizer (2006) demonstrates that a considerable proportion of Burkinabe women with unmet need would in fact not mind becoming pregnant. This ambivalent attitude might be more common in societies where childbearing ability is a mark of social status (Williamson, 2009). Furthermore, the risk of having another child at a non-ideal moment may seem less serious to some Burkinabe' who are living in precarious conditions, and who find comfort in the idea that having many children may increase the chances that one of them may help their parents out of poverty (Rossier et al. 2013). However, in this context, a woman's attitude towards a potential future pregnancy may also be influenced by her assessment of the social and economic costs of seeking FP, coupled with the perceived likelihood of side effects and lack of support. Often, the latter may outweigh the costs involved in accepting the risk of another pregnancy. Although the priority is addressing the unmet need of the women who report that becoming pregnant at a given time would be a significant problem, the ambivalence of the rest may well mean that they could be receptive to FP messages (Rossier et al. 2013). For these, improving the quality of services and facilitating access have the potential to tip the balance of costs and benefits in favour of contraception (Rossier et al, 2013). Improving FP service quality, and particularly that of client-provider interactions, can increase knowledge, client satisfaction and effective use (RamaRao, 2003).

\section{Strengths and limitations}

The main limitation of the study is that fieldwork was conducted in four health centres in a single health district, meaning that findings are not necessarily generalisable to the rest of the Bobo-Dioulasso area, nor to the country as a whole. The small numbers of stakeholders recruited due to time and resource constraints mean that their views are not necessarily representative of those held by their counterparts nationwide. Another limitation is that all findings related to demand and levels of information only apply to actual service users, and not to women who don't attend routine pregnancy or postpartum care or seek contraception at government health centres. Due to time limitations, it was not possible to organise interviews with men during this study, nor to observe whether FP advice is given during child health check-ups or vaccination sessions. For the same reasons, care in hospitals or in the community was not observed, and the decision was made to focus on primary care facility-based services.

However, this choice was based on the realisation that the CSPS constitutes the main interface with the health system for most users of $\mathrm{MCH}$ and FP services, thus the study can still provide valuable information on the level 
of care accessible to the majority of the population. Furthermore, stakeholders who worked or had experience of other health care settings were interviewed, thus contributing to giving the study a broader outlook on the health service. Efforts were made to include a variety of individuals from different professional backgrounds, who contributed considerably different perspectives. The choice of health district contributed to the possibility of observing potential diversity between urban and rural areas. This study adds valuable information about service quality based on a thorough examination of policies and guidelines, and on an assessment of care through nonparticipant observation which was enriched by the researcher's own clinical knowledge. 


\section{Conclusion and Recommendations}

In Burkina Faso, barriers limiting the availability and access to PPFP services are likely to be the reason why high levels of unmet need for contraception persist. This study has identified key areas for improvement which should be prioritised. These are summarised as follows.

Firstly, steps need to be taken to improve the quality of PPFP services. The presence of competent and motivated health workers who are authorised and supported to provide good care must be guaranteed. In this regard, areas for action include pre-service and in-service training and staff supervision and support, and consideration should be given to enabling accoucheuses to be trained to provide LARC. Adherence to current clinical guidance should be improved, especially in relation to the provision of counselling and information. Within largely adequate clinical guidelines, improvements could be brought to the PN guidelines to ensure that FP counselling is given more prominence. The improved competence of staff will contribute to making a broader range of contraceptive methods available throughout the country. Action is also needed to prevent the recurrence of stock shortages.

Secondly, in order to facilitate access and improve attendance, it is necessary to make better use of existing opportunities to promote FP along the continuum of care, according to and beyond current policy. Full implementation and improvement of the ANC guideline would ensure that FP is addressed during ANC, and further steps could be taken to promote postpartum and PPFP preparation, alongside birth preparation. The full elimination of user payments for contraception is needed in order to facilitate access, especially for the most disadvantaged women.

Finally, it is necessary to start to challenge the widespread assumption that traditional culture is irredeemably hostile to FP, and to realise that high quality services have the potential to stimulate demand. In this regard, providing individualised counselling and enabling informed choice must become part of routine practice. For this purpose, the development of a relationship of mutual trust between provider and client is crucial. Promoting the involvement of men also has the potential to increase the legitimacy and the uptake of PPFP. 


\section{References}

Abdel-Tawab N, Loza S, Zaki A, 2008. Helping Egyptian women achieve optimal birth spacing intervals through fostering linkages between family planning and maternal/child health services. FRONTIERS Final Report.

Adanikin Al, Onwudiegwu U, Loto OM, 2013. Influence of multiple antenatal counselling sessions on modern contraceptive uptake in Nigeria. European Journal of Contraception and Reproductive Health Care. Jul 25. [Epub ahead of print]

Alfieri C and Taverne, 2000. Ethnophysiologie, regles et precautions chez les Bobo Madare et les Mossi. In: Allaitement et VIH en Afrique de l'Ouest: De l'antropologie a' la sante' puiblique. Paris: Karthala

Alfieri C, 2000. Allaitement et parente' en pays bobo madare. In: Allaitement et VIH en Afrique de l'Ouest: De l'antropologie a' la sante' publique. Paris: Karthala

Amnesty International, 2009. Donner la vie, risquer la morte: la mortalite maternelle au Burkina Faso. London: Amnesty International

Assemblee Nationale, 2005. Loi n. 049-2005/AN portant en matiere de Sante de la Reproduction. Ouagadougou: Assemblee Nationale.

Barber SL, 2007. Family planning advice and postpartum contraceptive use among low-income women in Mexico. International Family Planning Perspectives Mar;33(1):6-12.

Becker S 1999 Measuring unmet need: wives, husbands or couples? International Family Planning Perspectives, 1999, 24(4):172-180

Becker S, Ahmed A, 2001. Dynamics of contraceptive use and breastfeeding during the postpartum period in Peru and Indonesia. Population Studies, 55, 165-179.

Bongaarts J, Potter RG, 1983. Behaviour, biology and fertility behavior: an analysis of the proximate determinants. New York: Academic Press.

Bongaarts J, 1994. Population policy options in the developing world. Science 263: 771-775

Bongaarts J, 2008. Fertility transitions in developing countries: progress or stagnation? Studies in Family Planing, 39(2), 105-110.

Bonnet D,1988. Corps biologique, corps social. Procréation et maladies de l'enfant en pays mossi, Burkina Faso. Paris, Ed. de l'ORSTOM, Coll. Mémoires, $n^{\circ} 110$.

Brown M, 2007. When ancient meets modern: the relationship between postpartum non-susceptibility and contraception in Sub-Saharan Africa. Journal of Biosocial Science, 39, 493-515.

Bruce J, 1990. Fundamental elements of the quality of care: a simple framework. Studies in family planning 21,2: $61-91$

Bulatao RA, Palmore JA, Ward SE, eds. 1989. Choosing a contraceptive: method choice in Asia and the United States. Boulder: Westview Press.

Campbell M, Sahin-Hodoglugil NN, Potts M. 2006. Barriers to fertility regulation: a review of the literature. Studies in family planning (37)2: 87-98.

Chiou C-F, Trussell J, Reyes E, Knight $\mathrm{K}$ et al 2003. Economic analysis of contraceptives for women. Contraception 68: 3-10 
Cleland J, Bernstein A, Ezeh A, Faundes A, Glasier A, Innis J, 2006. Family planning: The unfinished agenda. The Lancet 368: 1810-1827

Cleland J, Ndugwa R, Zulu E, 2011. Family planning in sub-Saharan Africa: progress or stagnation? Bulletin of the World Health Organization 89: 137-143

Dehne KL, 2003. Knowledge of, attitudes towards, and practices relating to child-spacing methods in Northern Burkina Faso. Journal of Health, Population and Nutrition, 21, 55-66.

Ecole de Sante Publique 1999. Programme de formation des agents de premiere ligne. Ouagadougou: Ecole de Sante Publique.

Hubacher D, Mavranezouli I, McGinn E, 2008. Unintended pregnancy in Sub-Saharan Africa: magnitude of the problem and potential role of contraceptive implants to alleviate it. Contraception 78, 73-78

Institut National de la Statistique et de la Démographie (INSD) et ORC Macro, 2004. Enquête Démographique et de Santé du Burkina Faso 2003. Calverton, Maryland, USA: INSD et ORC Macro.

Institut national de la statistique et de la démographie (2008), Recensement général de la population et de l'habitation (RGPH) de 2006 du Burkina Faso-Résultats définitifs. Ouagadougou: INSD.

Institut National de la Statistique et de la Démographie (INSD) et ICF International, 2012. Enquête Démographique et de Santé et à Indicateurs Multiples du Burkina Faso 2010. Calverton, Maryland, USA : INSD et ICF International.

Johnson-Hanks J, 2002. On the Modernity of Traditional Contraception: Time and the Social Context of Fertility. Population and Development Review (28) 2:229-249

Mason KO, Smith HL, 2000. Husbands versus wives' fertility goals and contraceptive use: The influence of gender context in five Asian countries. Demography 37:299-312.

Matheny G, 2004. Family planning programs: getting the most for the money. International Family Planning Perspectives Sep;30(3):134-8.

Miller R, Fisher A, Miller K, Ndhlovu L, Ndugga Maggwa B, Askew I, Sanogo D, Tapsoba P, 1997. The situation analysis approach to assessing family planning and reproductive health services: a handbook. New York: Population Council.

Ministry of Health, 2002. Circulaire $n^{\circ} 0277 / M S / S G / D A F$ du 5 février 2002 sur la gratuité des activités de soins préventifs portant sur la consultation prénatale des femmes enceintes. Ouagadougou: Ministry of Health.

Ministry of Health, 2005. Plan Strategique de securisation des produits contraceptifs 2006-2015. Ouagadougou: Ministry of Health

Ministry of Health, 2006 a. Stratégie nationale de subvention des accouchements et des soins obstétricaux et néonatals d'urgence: Burkina Faso. Ouagadougou: Ministry of Health.

Ministry of Health, 2006 b. Plan d'acceleration de Reduction de la Mortalite Maternelle et Neonatale au Burkina Faso - Feuille de Route. Ouagadougou: Ministry of Health.

Ministry of Health, 2009 a. Plan Strategique de securisation des produits de la sante de la reproduction 20092015. Ouagadougou: Ministry of Health

Ministry of Health, $2009 \mathrm{~b}$. Rapport d'analyse situationnelle de la profession sage femme et maieuticien d'Etat au Burkina Faso en 2009. Ouagadougou: Ministry of Health 
Ministry of Health, 2010 a. Politique et normes en matiere de Sante de la Reproduction. Ouagadougou: Ministry of Health

Ministry of Health, 2010 b. Protocoles de Sante de la Reproduction: composantes communes. Ouagadougou: Ministry of Health.

Ministry of Health, 2010 c. Protocoles de Sante de la Reproduction: Sante de la femme et du nouveau-ne de moins de sept (7) jours. Ouagadougou: Ministry of Health

Ministry of Health, $2010 \mathrm{~d}$. Guide de supervision des prestataires en soins obstetricaux, planification familiale et prevention de la transmission du VIH de la mere a l'enfant. Ouagadougou: Ministry of Health

Ministry of Health, 2011 a. Plan National de Developpement Sanitaire 2011-2020. Ouagadougou: Ministry of Health.

Ministry of Health, 2011 b. Directive N. 2011 - 0754/MS/SG/DGS/DSF. Objet: Couts de prestation des actes d'insertion et de retrait des implants et du DIU, 7 Avril 2011. Ouagadougou: Ministry of Health

Ministry of Health, 2012 a. Directive N. 2012 - 4700/MS/SG/DGS/DSF. Objet: Surveillance des stocks des produits de la santé de la reproduction. Ouagadougou: Ministry of Health

Ministry of Health, 2012 b. Annuaire statistique de la santé. Ouagadougou: Ministry of Health

Ministry of Health, 2012 c. Formation des prestataires en planification familiale clinique - Cahier du participant et guide du formateur. Ouagadougou: Ministry of Health and USAID/UNFPA

Ministry of Health, 2013. Plan national de relance de la Planification Familiale 2013 - 2015. Ouagagougou: Ministry of Health

Ministry of Health and ENSP "Docteur Comlan Alfred A. Quenum", Direction des Etudes et des Stages 2012. Programme de formation des Sage Femmes/Maieuticiens d'Etat. Ouagadougou: Ministere de la Sante

Ministry of the Economy and Finances and National Council for Population, 2000. Politique nationale de population du Burkina Faso. Ouagadougou: Ministry of the Economy and Finances

Ministry of the Economy and Finances, 2011. Strategie de croissance et developpement durable 2011-2015. Ouagadougou: Ministry of the Economy and Finances

RamaRao RM, 2003. The Quality of Family Planning Programs: Concepts, Measurements, Interventions, and Effects. Studies in Family Planning 34(4): 227-248

Ridde V, Morestin F, 2011. A scoping review of the literature on the abolition of user fees in health care services in Africa. Health Policy and Planning 26(1):1-11.

Rossier C, Senderowicz L, Soura A, 2013. The one God sends to save me: fertility desires and contraceptive practices among Burkina Faso's urban poor. IUSSP Working Paper

Rossier C, Hellen J, 2013. Family planning during the postpartum period in Ouagadougou, Burkina Faso: a qualitative supply and demand perspective. Paper presented at the Population Association of America Annual Meeting, New Orleans, April 11-13 2013

Page H, Lesthaeghe R, 1981. Child-spacing in Tropical Africa: Traditions and change. London: Academic Press.

Pariani S, Heer DM, Van Arsdol MD Jr, 1991. Does choice make a difference to contraceptive use? Evidence from east Java. Studies in family planning 22: 384-90. 
Ross JA, Winfrey WL, 2001. Contraceptive use, intention to use and unmet need during the extended postpartum period. International Family Planning Perspectives, 27: 20-27.

Ross J, Hardee K, Mumford E, Eid S, 2002. Contraceptive method choice in developing countries. International Family Planning Perspectives 28: 32-40

Santelli J et al. 2003. The measurement and meaning of unintended pregnancy. Perspectives on Sexual and Reproductive Health, 35(2): 94-101

Seiber EE et al. 2005. Maternal and child health and family planning service utilization in Guatemala: implications for service integration. Social Science \& Medicine, 61(2):279-291

Shapiro D, Gebreselassie T, 2008. Fertility transition in Sub-Saharan Africa: falling and stalling. African Population Studies 23(1), 3-23.

Singh S et al. 2009. Adding It Up: The Costs and Benefits of Investing in Family Planning and Maternal andNewborn Health. New York: Guttmacher Institute and UNFPA.

Smith KB, van der Spuy ZM, Cheng L, Elton R, Glasier AF, 2002. Is postpartum contraceptive advice given antenatally of value? Contraception. 65(3):237-43.

Speizer, 2006. Using strength of fertility motivations to identify family planning program strategies. International Family Planning Perspectives. 32(4):185-91.

Sullivan B, Rice J, Shelton JD, 2006. Skewed contraceptive method mix: why it happens, why it matters. Journal of Biosocial Science 30(4): 501-521

Trussell J, Vaughan B, Stanford J, 1999. Are all contraceptive failures unintended pregnancies? Evidence from the 1995 National Survey of Family Growth. Family Planning Perspectives 31(5): 246-247 \& 260

Williamson LM, Parkes A, Wight D, 2009. Limits to modern contraceptive use among young women in developing countries: a systematic review of qualitative research. Reproductive Health (19)6:3

World Health Organization,2004 a. Selected practice recommendations for contraceptive use. Geneva: WHO

World Health Organization, 2004 b. Reproductive Health Strategy to Accelerate Progress Towards the Attainment of International Development Goals and Targets. Geneva: WHO

World Health Organization, 2005. World Health Report 2005: Make every mother and child count. Geneva: WHO World Health Organization, 2010. Medical eligibility criteria for contraceptive use. Fourth edition. Geneva: WHO World Health Organization, 2011. Family planning: a handbook for providers. 2011 Update. Geneva: WHO World Health Organization, 2012. Optimizing health worker roles to improve access to key maternal and newborn health interventions through task shifting. Geneva: WHO.

World Health Organization (WHO), USAID, Jhpiego, MCHIP, 2012. Statement for Collective Action for Postpartum Family Planning. Unpublished.

Zerai A, Tsui AO, 2001. The relationship between prenatal care and subsequent modern contraceptive use in Bolivia, Egypt and Thailand. African Journal of Reproductive Health 5(2):68-82 


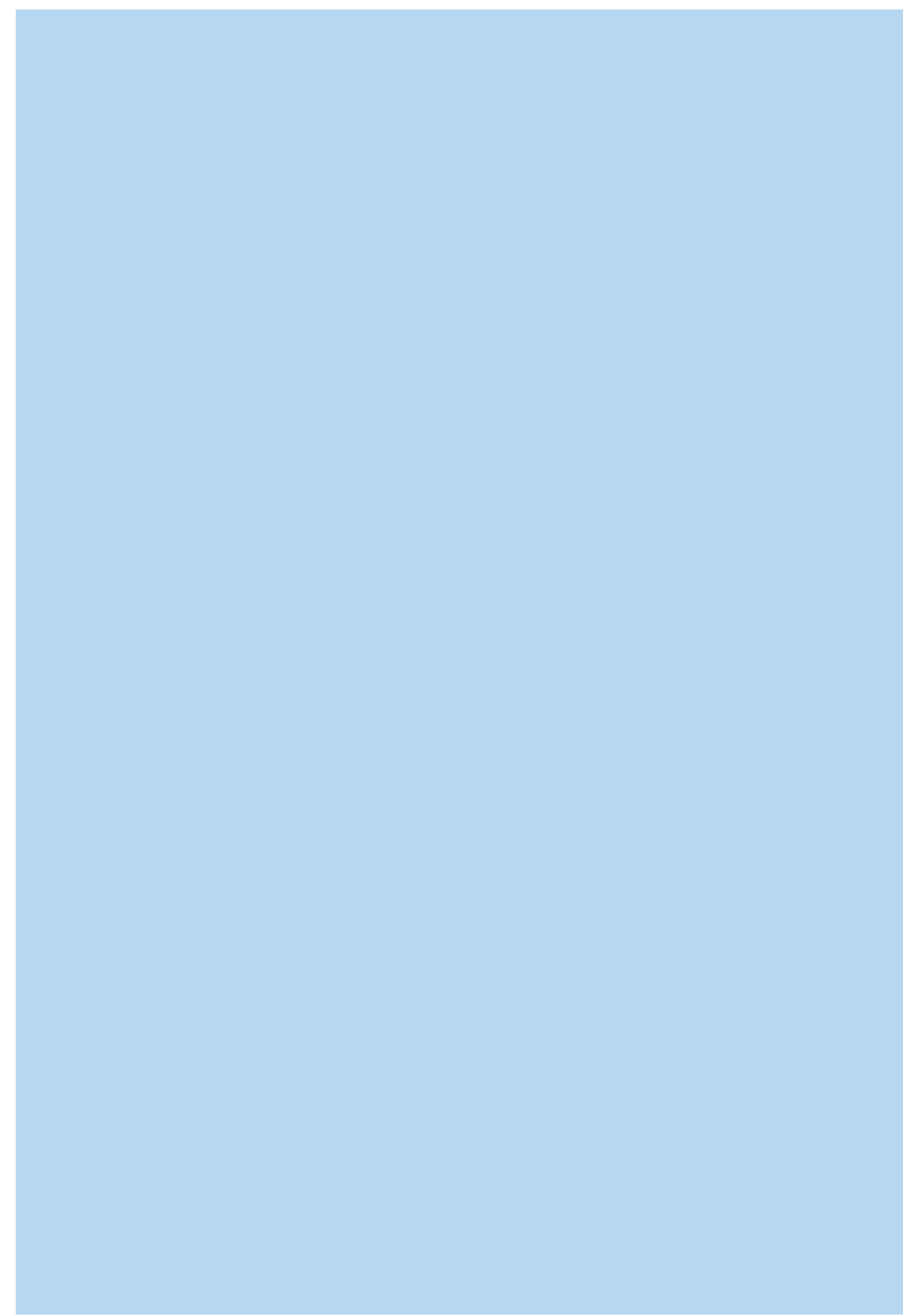

